\title{
ONTARIO'S EXPERIMENT WITH PRIMARY CARE REFORM ${ }^{\dagger}$
}

\section{Arthur Sweetman and Gioia Buckley}

\section{SUMMARY}

For the past decade-and-a-half, the government of Ontario has been implementing sweeping reforms in an effort to improve primary health care delivery. Altering physician-compensation models is central to this initiative. One measure of the scale of change is that in 2000 roughly 95 per cent of general/family practitioners were paid traditional fee-for-service, but by 2013 that proportion had plunged to just 28 per cent.

The province has clearly succeeded in largely replacing the traditional fee-for-service payment structure with blended payment models that are mostly group-oriented and include:

1) capitation (in some cases): a single payment for providing a particular "basket" of services to a patient for a fixed period, for example a year, regardless of the number of services provided,

2) fee-for-service payment, for services outside the capitated basket and provided in special situations, and

3) various bonuses and incentives (sometimes called pay-for-performance) that mostly focus on preventive care and the management of chronic conditions.

Physicians in rural and northern areas, as well as some clinics, also have salary and similar models as options.

Ontario has simultaneously introduced patient "rostering" - the formalized connecting of one patient to one physician and/or physician team/group - creating a relationship better suited to delivering preventive healthcare services. However, when surveyed, many patients are unaware that they have been "rostered" meaning that at present much of the benefit must be derived from the physician side alone. It remains to be seen whether or not it is important for patients to be aware that they are rostered. Beyond its clinical benefits, rostering has appreciable rhetorical and political value, as well as potential as a planning tool in efforts to ensure that the local and provincial supply of primary care is appropriate.

In a health-care system as large and complex as Ontario's, reform is more evolutionary than revolutionary; but the province has arguably moved rapidly within this context. Expenditures have been substantial and the initiatives groundbreaking. However, the same challenges that make reform a formidable undertaking also make it difficult to readily, or quickly, measure success, especially since many changes are ongoing. It is not yet demonstrably clear to what degree the government's goals are being achieved.

At present, there are mixed and conflicting findings about whether some of these changes have moved the health system towards the intended goals of improving health-care access and quality, and patient satisfaction, let alone whether the potential improvements can justify the resources expended to achieve them.

Naturally, those results we do have at this point offer insight only into the short-term effects of these changes. Especially, it is too early for sufficient evidence to have accumulated on the impact of new physician-group models on downstream costs, including drug prescriptions, specialist care, hospital costs and the use of diagnostic tests. These are, however, central questions that will in large part determine success. Also, it appears that the Ontario government could have accomplished nearly all of its goals so far without having implemented capitation, although capitation may prove beneficial in the longer term as the scarcity of physicians since the 1990s seems to be shifting towards a surplus.

In this new era, the health ministry will likely need to take a more hands-on role than it has in the past, including improved system monitoring. Going forward many stakeholders should be involved in evaluating this experiment on an ongoing basis to ensure that it is serving the healthcare needs of the population in an effective and efficient way.. 


\section{INTRODUCTION}

Over the past 50 years, Ontario's primary care physician-payment models, with one or perhaps two exceptions, can be characterized as having two features. First, they have been evolutionary rather than revolutionary; that is, there have not been marked turning points in direction as witnessed in some jurisdictions. Second, there has been accommodation for local initiatives, many of which have been long lived. Perhaps oddly, despite success, these local models have tended not to propagate. In terms of the exceptions, the seminal and undebatable revolution was the introduction of public medical insurance in 1966. As part of the federally financed wave of provincial medicare reforms, this innovation dramatically altered the face of health-care delivery in Ontario and Canada. Potentially, the second such major reform has been the move since the early 2000s towards provider payment and primary care delivery models involving the rostering of patients, teamwork and other "alternative" characteristics. However, this latter change also involves substantial elements of evolution and it could be argued that neither evolution nor revolution is the appropriate metaphor. Rather, the gradual turning of a large ship onto a new course might be the preferable analogy. It is this change of course on which we focus.

This paper provides relevant background and then describes and discusses the transformations of the most recent decade-and-a-half. The first section provides a brief look at selected economic issues from a theoretical perspective to assist in thinking about how to interpret the program of reform that is occurring. Substantial emphasis is placed on the role of changing risk in the movement from one model to another. In the next section is a brief history of the main primary care physician-payment models introduced in Ontario over the past 50 years. ${ }^{I}$ Subsequently, a brief survey of the empirical analyses of the recent physician-payment models is undertaken seeking to address the fundamental question of whether the move to the new models has paid off. The final section draws conclusions regarding what we can learn from Ontario's experience.

\section{PRIMARY CARE PAYMENT MODELS: AN ECONOMIC PERSPECTIVE}

A variety of primary care payment models have been implemented in various jurisdictions at different times. Each has had policy rationales, and associated economic incentives. Often, the scope of the incentives for behaviour has not been fully anticipated and only became obvious gradually, and at least as frequently hoped-for behavioural changes in response to a new design for an economic payment mechanism have not been as expected. The three most common basic payment schemes are fee-for-service (FFS), capitation, and fee-for-time (commonly called salary or a sessional fee, although it need not imply an employment relationship). Combinations of these three are common in single income streams, and many physicians also have diverse streams of income, all of which makes the full remuneration package quite complex for many individuals. For policy-makers, the environment is much more complex still since pay policy must recognize not only the diversity of each physician's remuneration package, but also the diversity that exists across individual physicians. Moreover, physicians have a range of tastes/preferences and therefore varied responses to a single policy, and most physician-pay

1 For a more extensive history of many of the models presented here, please see: M. Aggarwal, "Primary Care Reform: A Case Study of Ontario," dissertation (University of Toronto, 2009). 
policies have ramifications (spillovers) for other practitioners and the broader health-care "system." Review articles discussing these issues in an international context include Baker, Christianson and Conrad, Léger, and McGuire. ${ }^{2}$ Papers addressing Canadian health care are by Hurley et al., Hutchison et al., and Léger. ${ }^{3}$

Despite their limitations, the basic incentives inherent in the structure of each payment system seem to have some predictive power. Focusing initially on FFS and capitation, the left-hand side of Figure 1 is an illustration of a stylized practice (dark line) with both fixed costs (e.g., office-space rental and education/training) and variable costs (e.g., electricity and staff time). Of course, in real life, the distinction between the two can involve areas of grey on the margin (e.g., some share of electricity costs are fixed with the remainder being variable), but the concepts remain useful. Note that this conceptualization is distinct from the commonly discussed idea of physician billing comprising both her/his own remuneration as well as overhead. A physician's take-home pay comprises both fixed components (e.g., insurance and education) and variable components (e.g., hours of work), as does overhead, and, in practice, physician take-home pay in the Canadian context is often a residual, since the practice is commonly an owner-operated business and the physician (or her/his incorporated business), as the effective equity holder, receives the difference between total receipts (public billings plus private revenue) and non-physician costs. ${ }^{4}$ Also, on the left of Figure 1 is a schematic of FFS (dotted line) and pure capitation (dashed horizontal line), with the break-even point set at the same number of services for both. FFS has negative profits to the left of that point and makes positive profits to the right of it. In contrast, capitation has positive profits to the left, and losses to the right. This simple illustration points to two often-discussed incentives: FFS encourages an excess supply of services, whereas capitation encourages an undersupply. Of course, the payment mechanism is only one factor driving the supply of services. Training and practice styles, patient demand, tort law, and a variety of other influences are also relevant.

2 L. Baker, "Managed Care," in The Oxford Handbook of Health Economics, ed. S. Glied and P. C. Smith (Oxford: Oxford University Press, 2011), 405-431; J.B. Christianson and D. Conrad, "Provider Payment and Incentives," in The Oxford Handbook of Health Economics, ed. S. Glied and P. C. Smith (Oxford: Oxford University Press, 2011), 624-648; Pierre Thomas Léger, "Physician Payment Mechanisms," in Financing Health Care: New Ideas for a Changing Society (Weinheim: Wiley-VCH, 2008), 149-176; T. G. McGuire, "Physician Agency and Payment for Primary Medical Care," in The Oxford Handbook of Health Economics, ed. S. Glied and P. C. Smith (Oxford: Oxford University Press, 2011), 602-623.

3 J. Hurley et al., "Policy Considerations in Implementing Capitation for Integrated Health Systems," Centre for Health Economics and Policy Analysis, Policy Commentary Series Paper C99-01 (Hamilton, Canada: McMaster University, 1999); B. Hutchison et al., "Capitation Formulae for Integrated Health Systems: A Policy Synthesis," Centre for Health Economics and Policy Analysis, Policy Commentary Series Paper C99-02 (Hamilton, Canada: McMaster University, 1999); B. Hutchison et al., "Primary health care in Canada: systems in motion," The Milbank Quarterly 89, 2 (2011): 256-288; Pierre Thomas Léger, "Physician Payment Mechanisms: An Overview of Policy Options for Canada" (Ottawa: Canadian Health Services Research Foundation, 2011).

4 Multiple physician practices typically have sharing rules among the various partners, and some may have a form of profit sharing among the staff or other mechanisms for dividing revenues among non-physicians. 
On the right-hand side of Figure 1 is the same practice-cost schematic, but overlaid on it is a blended capitation and FFS model with a similar break-even point to that on the right. In very broad terms, the way it is drawn also reflects a characteristic that is (partly) the case for Ontario, and is also recommended by, for example, McGuire. ${ }^{5}$ That is, the capitation rate should exceed the fixed costs and the FFS component should be less than the marginal cost of service-provision to constrain excess provision given patient and practitioner preferences, especially in a fully insured context. The schematic clearly illustrates the central advantage of the blended model in aligning incentives and avoiding the pitfalls of the FFS and capitation extremes. Of course, translating a simple schematic to the diversity of the "real world" raises many implementation issues. The informational and management requirements for model development and ongoing execution are probably greater for the blended model than for the two pure models (or, at least, FFS), and the possibility of setting crucial parameters incorrectly could make a simpler model such as FFS preferable. However, if the increased complexity can be appropriately addressed, then the benefits from aligning incentives are potentially appreciable.

FIGURE 1: ILLUSTRATIVE SKETCHES OF FFS AND CAPITATION (LEFT), AND BLENDED (RIGHT) PAYMENT MODELS

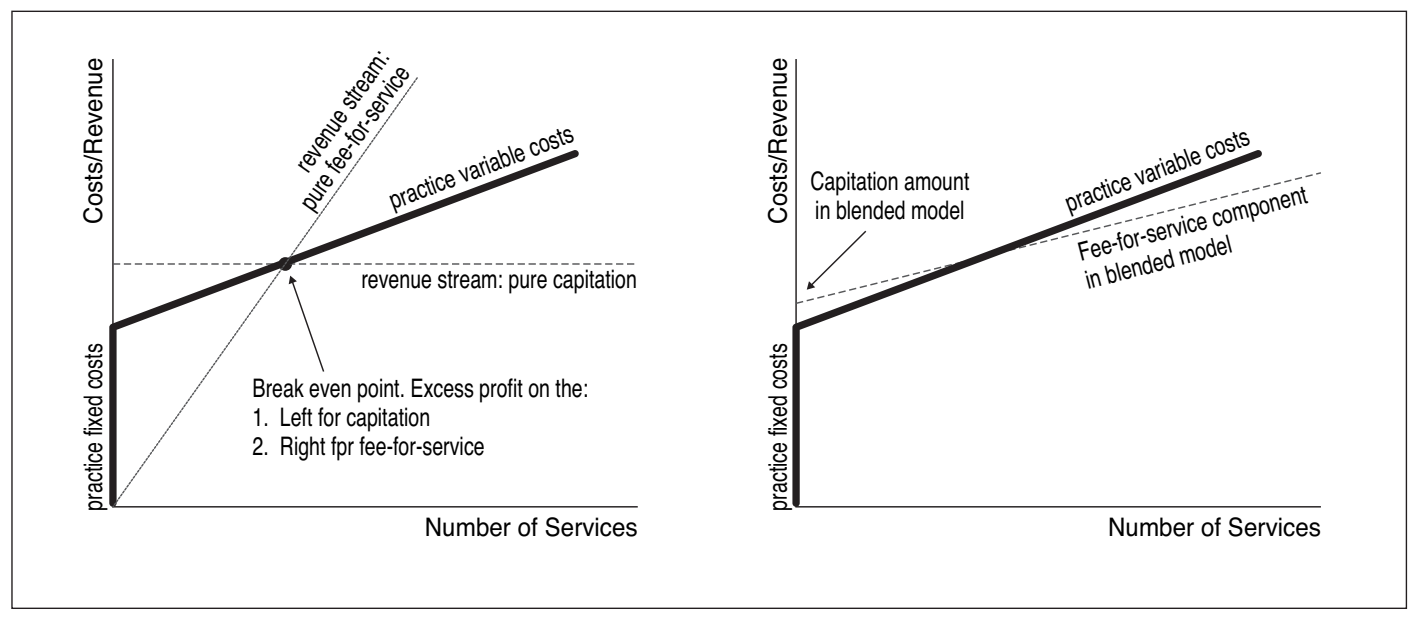

Two common features of capitated models are rostering/enrolment, and group/team and sometimes interdisciplinary practices (more on this below), although neither characteristic is exclusive to capitation. First, capitation and blended capitation models involve "enrolment," also known as "rostering," whereby a patient is invited to voluntarily commit to contact the primary care physician they are enrolling with for all primary medical advice or treatment, except in cases of emergency or while away from home. The primary care practice typically also makes certain access commitments. Enrolment/rostering provides a one-to-one correspondence between the patient and the practitioner or practice. However, rostering is a general mechanism that can extend beyond capitated practices, and once it is in place it allows certain types of payment models that are otherwise difficult. FFS is commonly unidirectional. Patients go to a physician (sometimes different physicians) when they have a medical problem, but it is difficult to identify which physicians are "responsible" for which patients in order to

5 McGuire, "Physician Agency." 
pro-actively provide preventive services or manage chronic conditions. Enrolment clarifies the correspondence and permits payments for attaining targets such as a certain share of relevant enrolled patients receiving a particular screening test or vaccination. Once the value of enrolment is appreciated, it can be extended beyond capitation. Second, although it is not necessarily a feature of capitation, the model is commonly associated with group and interdisciplinary practices. In part, this latter characteristic is desired by payers who usually see it as useful for improving quality, delivering preventive care, and managing chronic medical conditions. Also, although not always considered in planning, group practices effectively diversify the risk associated with capitation, which has some benefits.

\section{Transferring Risk}

As has been pointed out by many health economists, one of the key functions of capitation is to transfer a type of risk from the payer (usually the province, in the Canadian context) to the primary care practice/physician. This may strike economists not involved in health care as odd. Usually, it is desirable to avoid/reduce risk through diversification, which implies carrying it at the largest scale of operations possible: that is, for the province rather than the primary care practice to carry the risk. Capitation is motivated by the idea that carrying no risk at all, in a world where risk is very real, distorts physicians' decisions. A commonly cited facet of facing too little risk is that physicians and patients might under-invest in preventive care. If this is the case, then Canadian public insurance (medicare), combined with FFS, is a situation where the incentives are most misaligned. Physicians receive more pay for providing more services, and patients do not pay risk premiums, co-payments, deductibles or the like for the financial costs of their care. In making a single annual payment for all primary care services, traditional "pure" capitation encourages preventive care to reduce future health-care service demands.

It's worth clarifying exactly what transferring risk means in this case. Compared to FFS, capitation stabilizes government payments and physician billings over time and, at first blush, this may appear less risky to both. But consider this stable income flow in the face of various types of health shocks that might cause the demand for health-care service delivery to change given that, in any year, five per cent of patients account for roughly two-thirds of costs. Some health shocks occur in a relatively slow and predictable manner caused by such factors as population aging, and are addressed relatively easily. Idiosyncratic health shocks, such as a province-wide influenza outbreak, might impact the entire provincial health-care system. Other than that, shocks might be at a more local or at a practice level; a local infectious-disease outbreak or even a major accident might increase the demand for services. At the level of an individual patient, any number of negative health shocks (e.g., accidents, the onset of disease, etc.) may increase the demand for health services. In the opposite direction, positive health shocks would decrease the demand for health services.

In any well-functioning health-care delivery system, the quantity and composition of services delivered adjusts in response to shocks. Under an FFS model, billings adjust so that provider remuneration per service is constant and the risk is borne by the payer/province in the form of fluctuating payments (mildly fluctuating given diversification). In contrast, under "pure" capitation, each practice's hours of work, effort and variable costs of providing primary care services shift over time, but total billings do not. Since physicians are the residual claimants of each practice's billings, their annual take-home pay is predicted to vary inversely with their 
effort/hours. Of course, physicians can shift some of the costs onto patients in the form of longer wait times and reduced services for patients with non-acute care requirements when practices are busy, although some would argue that doing so breaches the "deal" on which capitation is founded. Additionally, in busy times, work can be shifted to (or, when less busy, from) emergency rooms, drop-in clinics, specialists or other sources of delivery that may or may not be compensated by the capitated physician, with there being an incentive to shift such services to forms of delivery not compensated by the capitated model.

Looking at the big picture, it may be that "pure" capitation transfers too much risk. Capitation was attempted in the U.S. in the 1980s and 1990s, and Robinson ${ }^{6}$ points out that some U.S. medical practices went bankrupt following "bad luck" in the random distribution of health shocks. Partly this was due to poor governance models that encouraged bankruptcy as opposed to swings in the hourly rate of remuneration for physicians (of course, there were fewer complaints from those practices that experienced an abnormal number of positive health shocks). As pointed out by Rosenthal et al., ${ }^{7}$ capitation was frequently the payment form between the insurance company and the legal entity that was the practice (e.g., a limited liability partnership, or a formally incorporated firm), but the physicians were frequently paid salary and/or FFS. The practice/corporation in this case suffered financial intermediation problems resulting from the mismatch in revenues and expenditures. An extremely negative draw in patient demand would drive it into bankruptcy, since the costs of servicing that high level of demand were higher than the fixed remuneration received via capitation. In the latter part of the 1990s, physicians in the United States became dissatisfied with capitation and were unwilling to accept the associated risk given the modest risk premium (implicitly) paid. Pure capitation receded as a payment model in primary care. A useful survey of many of these issues is by Newhouse ${ }^{8}$ who characterizes the optimal payment model as needing to (among other issues) address a trade-off between moral hazard and risk aversion, which points to a blended payment model.

It is also worth considering the practicality of transferring risk to physicians, with a goal of increasing preventive medicine, when patients are mobile (or, more generally, the patientphysician bond is short term). We need to think carefully about how this might work in practice. Preventive care is a long-term investment, and if the time frame to recoup the investments is limited, then only preventive actions with a short-term payoff may be encouraged. More generally, this highlights the main beneficiary of preventive care - aside from the patient and in some cases perhaps more than the patient - as being the provincial treasury and the taxpayer. This follows from the fact that patients are more likely to change primary care practices than they are provinces. It also implies that provincial health ministries may be viewed as holding primary responsibility for preventive and other long-term investments that will reduce future health-care service consumption. In promoting prevention

6 J.C. Robinson, "The end of managed care," Journal of the American Medical Association 285, 20 (2001): $2622-$ 2628; J.C. Robinson, "Theory and practice in the design of physician payment incentives," The Milbank Quarterly, 79, 2 (2001): 149-177, III.

7 M.B. Rosenthal et al., "Transmission of financial incentives to physicians by intermediary organizations in California," Health Affairs 21, 4 (2002): 197-205.

8 Joseph P. Newhouse, "Reimbursing Health Plans and Health Providers: Efficiency in Production versus Selection," Journal of Economic Literature 34, 3 (1996):1236-1263. 
through advocacy, pay-for-performance schemes, and other such initiatives, many provinces are starting to act on this issue, which is perhaps becoming more pressing given population aging and straitened finances.

\section{Operationalizing a Blended Model}

Several issues need to be addressed in developing the policy framework for a blended model, and it needs to be kept in mind that there is no single response by physicians to any such policy. For example, primary care practices have a broad range of ratios of fixed-to-variable costs, so setting single capitation (fixed) and FFS (variable) components will have heterogeneous impacts on take-home pay across the range of practitioners. While employing a small number of sets of parameters - e.g., rural and urban - may alleviate this issue, it does not eliminate it. Naturally, this type of issue applies to all payment models, so the contest between models is one of degree. However, this type of heterogeneity can have substantial resource-allocation implications if practitioners self-select into their preferred payment model, as is the case in Ontario.

A key issue is the scope of services (set of billing codes) included in the capitation basket (also referred to as "core" or "capitated" services). As will be seen, in the current Ontario model the scope of the services is modest in number, including only "core" primary care services, although these billing codes are quite commonly employed and represent a large proportion of the services offered. If the capitated basket encompasses either a small share of total billings, or a very predictable/stable set of tasks, then it is less risky. Items might also be selected because they represent outcomes over which primary care physicians have some control (in a statistical sense) via, for example, the provision of preventive care (e.g., by providing diabetes management or flu shots - assuming both are effective). But, it might not, for example, include injuries from infrequent, large and costly accidents over which physicians arguably have little control. That is, the basket might be chosen because it transfers the "right type" of risk.

The size and structure of the FFS component needs to be decided, and blending can potentially occur on multiple dimensions. First, the existence of capitated and non-capitated services (those inside and outside of the capitated basket of primary care services) is itself a type of blending. Second, inside the capitated basket (and, in the extreme, the basket may consist of 100 per cent of primary care services) blending may entail a less than full-cost FFS payment for each service or a subset of the services provided. For example, payment for items in the capitated basket might include an aggregate capitation amount plus a small (less than marginal cost) FFS payment. A salary or payment-for-time component could also be employed. Third, practices may have a blend of patients funded under different payment models. Some patients might be blended capitation, and others traditional FFS. A larger share of FFS patients implies carrying greater per-patient risk for those on the capitated side of the practice. In Ontario's alternative payment models, all three of these forms of blending are observed (with pay-forperformance layered on top). This makes the incentives quite complex. This complexity matters in its own right since, if physicians do not understand their payment model, or remember its details, then the associated incentives are blunted or ineffective.

9 Of course, not all such initiatives are successful, and pay-for-performance plans have, at best, a mixed history as discussed in: J. Li et al., "Physician Response to Pay-for-Performance: Evidence from a Natural Experiment," Health Economics (Forthcoming). In part, this mixed success has to do with design and implementation issues. 
As an aside, it is worth noting that the capitation principle can extend beyond primary care. What is called "fund-holding" in the U.K. can be seen as a form of capitation, where specialist and hospital (even tertiary) care are all in the capitation basket. This effectively internalizes what are currently externalities in the Ontario system. For example, capitation's incentive to withhold services (to maximize profits, if profits are a prime motivator) could lead to increased emergency room use by capitated patients since there is no cost to the primary care practice from such use. In contrast, Ontario does impose limited financial costs on the practices of capitated patients who receive care from primary care physicians with whom they are not enrolled.

\section{CHRONOLOGICAL DESCRIPTION OF SALIENT PRIMARY CARE PHYSICIAN-PAYMENT MODELS IN ONTARIO}

Before turning to the more recent innovations that are the focus of this discussion, we present a brief synopsis of payment models under medicare. This era started with Ontario's introduction of universal publicly insured physician services, named the Ontario Medical Services Insurance Plan (OMSIP), the precursor to what is known today as the Ontario Health Insurance Plan (OHIP), on July $1,1966 .{ }^{10}$ Physicians licensed to practice in Ontario submit claims to the government for insured services provided to OMSIP/OHIP beneficiaries, which includes almost all Ontario residents. See Appendix 1 for a chronological summary of the relevant primary care payment models under the public system.

\section{Traditional Fee-for-Service}

Fee-for-service reimbursed the vast majority of claims in primary care for about 40 years in Ontario. Even in 2003, about 80 per cent of general practitioners were not part of an alternative payment model of any type and paid exclusively FFS for their primary care duties. However, by 2013 only about 28 per cent of primary health-care physicians remained pure FFS.

Nevertheless, as will be seen, those in certain alternative payment models continue to receive a majority of their billings as FFS as not all alternative models are capitated. The "price" of each service is listed in the periodically updated Schedule of Benefits for Physician Services. As discussed, this payment method creates the incentive to maximize the number of services provided. It is also an individualistic, physician-centred, model.

${ }^{10}$ Canadian Museum of Civilization website, "Making Medicare: The History of Health Care in Canada, 1914-2007 Glossary," http://www.civilization.ca/cmc/exhibitions/hist/medicare/medic-glossary_e.shtml; Government of Ontario website, "About the Ministry - History," http://www.health.gov.on.ca/en/ministry/history.aspx. 


\section{Alternative Payment Models: Early Models from the 1960s to 1998}

Even before medicare, Ontario experimented with a capitated and group-payment model. Prompted by local union members and residents of geographically isolated Sault St. Marie, Ontario contributed to the building and operation of the Group Health Centre (GHC). It is an interdisciplinary ambulatory health-care centre providing primary and specialty care that opened in 1963. The GHC is still in operation today and is "Ontario's largest and longest established alternatively funded healthcare organization" ${ }^{\prime l}$ and provides care to 80 per cent of the local population. ${ }^{12}$ GHC is a patient-enrolment model in which primary care physicians currently receive a blend of payment elements constituted primarily by capitation with the addition of some FFS payments and incentives (for example, after-hours premiums, payments for enrolling new patients, performance-based payments such as a special payment for providing care to at least five patients with a serious mental illness, a special payment for managing the care of a patient who has had heart failure or has been diagnosed with diabetes, and cumulative bonuses for providing preventive-care services such as flu shots and Pap smears). Allied (non-physician) health professionals such as nutritionists and pharmacists are salaried.

A second example of a community-based health-care organization is provided by Community Health Centres (CHCs), which began to establish in the 1970s. CHCs provide interdisciplinary primary health-care services where physicians work in a team with, for example, registered nurses, nurse practitioners, nutritionists, social workers, and chiropodists. CHCs serve geographical areas and neighbourhoods that are relatively more vulnerable to illness (e.g., those presenting higher proportions of immigrants, homeless and seniors; those with lowerthan-average income levels); or those with barriers to health-care-service access relative to the general population (e.g., rural and northern communities, and those with a higher proportion of people who speak neither English nor French). Between 2004 and 2006, when 55 CHCs were in operation, the Ontario Ministry of Health and Long-Term Care (MOHLTC, also referred to here as "the ministry") announced major investments to expand the successful CHC model across the province. Consequently, 21 new CHCs and 28 satellites were opened. ${ }^{13}$ Currently, there are $75 \mathrm{CHCs}$ in operation plus 28 satellites.$^{14}$ Primary care physicians in $\mathrm{CHCs}$ do not enrol their patients and are salaried employees. The GHC and the CHCs represent the oldest alternative payment models in Ontario.

11 Group Health Centre website, http://www.ghc.on.ca/about/content.html?sID=2.

12 Brian Mitchell, Breakout Session: “Thriving Models That Haven't Spread: Why Not?” Group Health Centre, Sault Ste. Marie, Ontario, http://www.cfhi-fcass.ca/Libraries/Picking_up_the_pace_files/Brian_Mitchell.sflb.ashx.

13 Association of Ontario Health Centres, "Ontario's Community Health Centres - Addressing the great health divide," (Toronto: Association of Ontario Health Centres, 2010); Government of Ontario, "Community Health Centres Take Big Step Forward," News Release, July 17, 2006, http://news.ontario.ca/archive/en/2006/07/17/Community-HealthCentres-Take-Big-Step-forward.html.

14 Association of Ontario Health Centres website, "Ontario's Community Health Centres - Who we serve," http://www.ontariochc.ca/index.php?ci_id=3003\&la_id=1; Association of Ontario Health Centres, Personal Communication, March 28, 2013; Government of Ontario website, "Community Health Centres,"

http://www.health.gov.on.ca/english/public/contact/chc/chc_mn.html. 
In 1973, a new voluntary model of primary health-care delivery, the Health Service Organization (HSO), was introduced. This model was made available to physicians with practice populations "ill suited for FFS payment because of the populations served." ${ }^{15}$ Initially, HSOs were globally funded, but capitation was made available beginning in $1978-79 .{ }^{16}$ Physicians could form an HSO either solo or as a group, and HSOs had the option of integrating non-physician providers (e.g., nurse practitioners). Capitation payments to HSOs were adjusted based on the age and sex of enrolled patients, and were made for providing a predefined basket of services. Services outside of this basket for enrolled patients were paid by FFS, as were those provided to nonenrolled patients, but FFS payments were capped to a maximum dollar amount. ${ }^{17}$ This blend of both capitation and FFS payment streams for services to enrolled patients is a feature of HSOs and of all subsequent capitation-based models. The HSO program expanded between 1987 and 1991 when the ministry stopped accepting new applications. Over 70 per cent of HSOs were located in Central and Southwestern Ontario. The HSO model no longer exists; it was absorbed by the new Family Health Organization (FHO) model introduced in 2006. At that time, there were 48 HSOs with 161 physicians (of about 10,700 GPs in the province in that year according to the Ontario Physician Human Resources Data Centre) and over 250,000 patients enrolled. Though small, this model allowed both the ministry and Ontario physicians to gain experience with blended payment models.

The 1980s and early 1990s saw additional new models initiated. Examples include the following (for a fuller list see Appendix 1):

- In Kingston, Ont., July 1994 saw the establishment of the Southeastern Ontario Academic Medical Organization (SEAMO), an association between: Queen's University, the Clinical Teachers' Association of Queen's University and Kingston's three principal teaching hospitals. SEAMO enters into multi-year Alternative Funding Plans (AFPs) with MOHLTC and the Ontario Medical Association in order to meet the complex overlap of these centres' academic and clinical goals. These AFPs most often provide non-FFS payments both for primary care physicians and for specialists. Physicians in SEAMO's primary care clinic, Queen's Family Medicine, receive a blended payment based on capitation. Currently, they are affiliated with the Family Health Network model described below.

- Community Sponsored Contracts (CSCs) and the Northern Group Funding Plan (NGFP): Introduced in 1996 and 1998 respectively, these two models were designed to attract physicians to rural and/or northern areas of the province and were characterized by a base remuneration (salary) for the physician, plus pay-for-performance payment/incentives. ${ }^{18}$ These models were converted into the Rural and Northern Physician Group Agreement in 2004.

15 Hutchison et al., "Capitation Formulae."

16 ibid.

17 For a while, this cap was set at $\$ 30,000$ for HSOs; this cap was then raised to $\$ 40,000$.

18 J. Hurley, P. DeCicca, J. Li and G. Buckley, "The Response of Ontario Primary Care Physicians to Pay-forPerformance Incentives Centre for Health Economics and Policy Analysis," Working Paper Series, Paper 11-02 (Hamilton, Canada: McMaster University, 2011). 
Other than the CHC model, which expanded throughout the province, the other models discussed above, many of which are still in operation today, are one-off local initiatives. ${ }^{19}$ By the end of the 1990s, over 90 per cent of primary care physicians were in the traditional FFS model. This was about to change, however, with a decade of transformation coined "Primary Care Reform" that generated a surge in the number of primary care physicians participating in alternative payment models.

\section{Alternative Payment Models: The Late 1990s and Primary Care Reform}

Primary care was established as a priority by the Ontario government and Primary Care Reform (PCR) was announced jointly by the Ministry of Health and the Ontario Medical Association in July $1996 .{ }^{20}$ The motivations behind this reform were:

- Lack of communication and information sharing across the health-care sector;

- Financial incentives built into the FFS remuneration model;

- Fragmentation of care as patients moved across the system;

- Uneven access to primary care;

- Increased numbers of "office only" primary care physicians. ${ }^{21}$

The main objectives of PCR were: ${ }^{22}$

- Improved patient access to care;

- Improved quality and continuity of care;

- Increased provider and patient satisfaction with the health-care system;

- Increased cost-effectiveness of health-care services.

From 1999 to 2006, a series of new primary care payment models were introduced, all presenting the following characteristics:

- Enrolment of patients encouraged or required;

- Population-based funding (capitation or "reformed" FFS);

- Team-based care (with at least one notable exception);

- After-hours service availability;

- Incentives for preventive care, and;

- For capitation-based models only, one-time payments to support the integration of information technology in the practice.

\footnotetext{
19 S. Farrar et al., "Integrated model for mental health care. Are health care providers satisfied with it?" Canadian Family Physician 47, 12 (2001): 2483-2488.

20 Ontario Ministry of Health and Long-Term Care and PriceWaterhouseCoopers, Evaluation of Primary Care Reform Pilots in Ontario: Phase I-Final Report, 2001.

21 ibid., 3 .

${ }^{22}$ Hutchison et al., "Capitation Formulae"; Ontario Ministry of Health and Long-Term Care and PriceWaterhouseCoopers, Evaluation.
} 
Primary Care Networks (PCNs) were pilot projects introduced in 1999. Remuneration was either a reformed FFS model, whereby payment is FFS as usual but claims are benchmarked to maximum billing levels based on age-sex adjusted capitation rates, or a blended system based on capitation; the majority of PCNs were in the latter model. PCNs differed from HSOs in a few ways: they had a minimum group requirement of five physicians, the capitation rates were different, new incentives (e.g., cumulative preventive-care bonuses, home-care supervision fee) were available, and the PCN agreement stipulated new obligations and payments associated with a Telephone Health Advisory Service (THAS) ${ }^{23}$ Many HSOs converted to PCNs in 19992000 .

\section{Alternative Payment Models: From 2002 to the Present}

Beginning in the late 1990s, "a new policy environment emerged" 24 and primary health care was identified as a priority not only in Ontario but across the country. Physicians wanting to join any model must sign an agreement with MOHLTC which details payment elements, service requirements and other contractual obligations required by the model. The signed contract is based on a template agreement negotiated between the Ontario Medical Association (OMA) and MOHLTC, often customized to the needs of the practice population and/or physician group. In addition to these template agreements, updates to the models (for example, extending eligibility for additional bonus payments) may also be included directly in the main MOHLTC-OMA Memorandum of Understanding, also known as a Physician Services Agreement (PSA) that is periodically re-negotiated.

The 2004-2008 MOHLTC-OMA Memorandum of Understanding introduced several additional initiatives for primary care models while beginning to align existing capitation and salarybased models. Examples are the amalgamation of some CSCs and the NGFP into a new model; the Rural and Northern Physician Group Agreement (RNPGA); SEAMO, GHC and HSOs being "harmonized" with other primary care reform models thereby becoming eligible for bonuses and incentives already available to other models. ${ }^{25}$ As HealthForceOntario describes it: ${ }^{26}$ "The three objectives underlying harmonization are to streamline the administration of agreements, reduce complexity in changes of payment systems and contract management, bring financial equity ('relativity') across primary health care models and participating physicians and make the model available to any physician in Ontario."

23 Introduced in 1999, the THAS is a nurse-staffed telephone line available to PCN patients for after-hours advice; a physician from the network is on call if required, otherwise the patient is directed by the nurse to either an emergency department or to self care. The PCN receives a monthly lump-sum payment for being on call for the THAS. Effective Jan. 1, 2013, the THAS is no longer a requirement of PCR models.

24 B. Hutchison et al., "Primary health care."

25 Also, beginning in 2005, HSOs (in July 2005) and SEAMO (in November 2005) began submitting their service data as claims to the MOHLTC and began receiving shadow-billing premiums. Previously, these models had tracked their services using distinct forms.

${ }^{26}$ HealthForceOntario, Health Human Resources Toolkit, 2007. 
Introduced in April 2002, the Family Health Network (FHN) is another voluntary blended capitation-based payment model. FHNs also came to have a minimum group requirement of three physicians, though the initial requirement was five. FHNs have payment streams and incentive structures somewhat similar to PCNs (e.g., age-sex-based capitation payments for a basket of services to enrolled patients, FFS payments for excluded services to enrolled patients, and capped FFS payments for services to non-enrolled patients, as well as incentives and bonuses). The main differences between PCNs and FHNs are the different capitation rates and the fact that FHNs began receiving a "shadow billing" premium and an "access bonus."

The shadow-billing premium for capitation-based physicians is an FFS element for services in the capitated basket for enrolled patients; the premium is also paid to salary-based physicians. The original purpose of the premium was not to blend payments as in Figure 1, but for accountability purposes, in that it aimed to encourage the submission of claims for capitated or salaried services. It is effectively a fee to support administrative compliance with billing. Nevertheless, it started a new type of blending. Shadow-billing premiums were paid to FHNs from their inception in April 2002 in the amount of 10 per cent of the FFS value of the services. They were then phased in for other models, and then as of October 2010 the shadowbilling premium was increased to 15 per cent for FHNs (and FHOs, presented later).

A common feature of capitation is a penalty imposed on the capitated physician when a rostered patient receives a capitated service from a primary care physician outside of the group. The rationale behind this penalty is to avoid the funder paying twice for the same services. In the PCN model, outside-use penalties were a negotiated percentage of the capitation rate, which was subtracted from the capitation payments. In the FHN model, physicians receive a semi-annual bonus equal to 20.65 per cent of the capitation payments received minus the FFS value of core services provided by other physicians. Financial penalties for outside use cannot exceed the bonus amount, so there is a clear maximum clawback. If we want to compare "apples with apples," then the capitation rate a physician receives when no outside use occurs is 100 per cent for the PCN, but 120.65 per cent of the nominal rate for the FHN. It is important to keep this in mind also when conducting comparisons with capitation rates used in other jurisdictions.

Family Health Groups (FHGs) are an enhanced FFS model with patient enrolment. It is an example of the benefits of enrolment being recognized and applied beyond capitation. The rostering of patients allows for incentives that encourage health targets. The FHG model was introduced in July 2003 for groups of three or more primary care physicians and considered as a potential transition model when moving from FFS to capitation. FHG physicians receive 100 per cent FFS payments plus bonuses and incentives. Among the added pay-for-performance incentives was a new comprehensive-care premium to encourage the provision of health assessments, preventive-care services (e.g., Pap smears, immunizations), diagnosis and treatment. After-hours care is also required, as is THAS. ${ }^{27}$

\footnotetext{
27 The FHG template letter defines comprehensive care as follows: "Comprehensive Care assumes that the care is part of an on-going process into the future and provides care in the patient's family and social context. It includes the creation, management and maintenance of an appropriate medical record managed by the physician." (Ontario Ministry of Health and Long-Term Care and Ontario Medical Association, Family Health Group Letter of Agreement, "Description of Comprehensive Care," Appendix B, 2003).
} 
The Comprehensive Care Management (CCM) model was introduced in October 2005 for physicians who wanted to opt for a payment model similar to the FHG, with its opportunity for higher remuneration, but wished to remain practicing solo. Similar to FHGs, CCMs are paid 100 per cent FFS as usual, plus some bonuses and pay-for-performance incentives.

Lastly, and quite importantly, as a result of the harmonization of HSOs and PCNs, Family Health Organizations (FHOs) were introduced on Nov. 1, 2006 for groups of three or more physicians. On this date, all existing HSOs and PCNs became FHOs. Similarly to earlier blended capitation-based models (HSOs, PCNs and FHNs), capitation is the primary source of income for FHO physicians, but they also receive FFS payments (for non-capitated services to enrolled patients, for all services to non-enrolled patients), shadow-billing premiums, after-hours premiums, plus various pay-for-performance bonuses and incentives.$^{28}$ FHNs and FHOs are eligible for the same premiums and incentives, the same after-hours requirements and payments, have the same shadow billing premium (15 per cent) and the same cap for capitated services provided to non-enrolled patients $(\$ 55,950)$. But, they differ in that the FHO basket of services is larger, having almost double the number of fee codes than the FHN basket (currently 132 fee codes as opposed to 69 for FHNs), which implies that their capitation rates and access bonuses are different. Also, for FHOs, the access bonus is 18.59 per cent of the capitated payments whereas it is 20.65 per cent for FHNs.

Both FHN and FHO capitation rates are based on 38 age-sex-specific ratios that multiply the base rate. They vary between 0.44 to 2.71 for FHNs and between 0.44 to 3.57 for FHOs. Base rates at the time of writing are $\$ 126.48$ for FHNs and $\$ 139.12$ for FHOs. The two figures below compare the FHN and FHO age-sex capitation ratios for females and males.

FIGURE 2: FHN AND FHO CAPITATION-ADJUSTMENT RATIOS, FEMALES

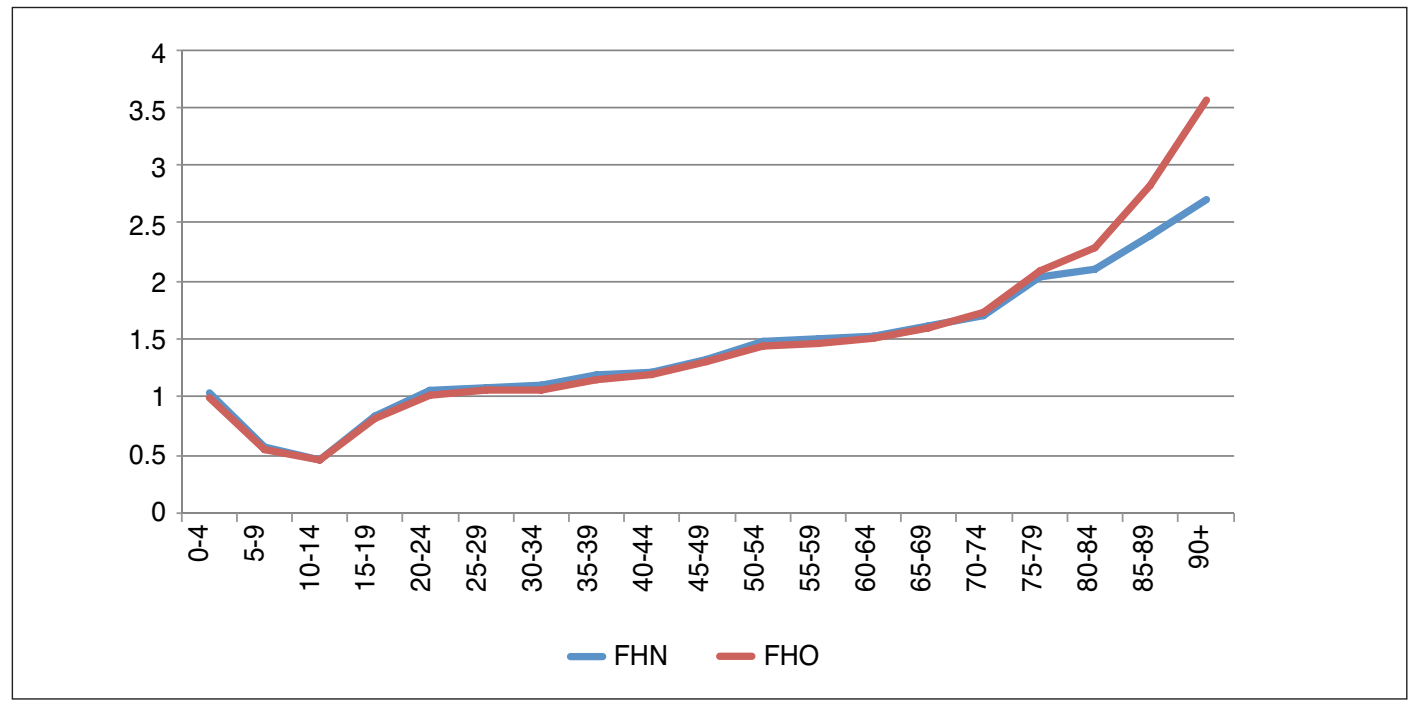

${ }^{28}$ For simplicity, here we refer to a primary care physician's income solely as the remuneration from the Ontario Ministry of Health and Long-Term Care for insured services to OHIP beneficiaries. Physicians may also receive other income streams, including payments from patients for uninsured services (e.g., the provision of medical certificates), payments for educational activities (e.g., teaching or supervising trainees) and consultations from third parties. 
FIGURE 3: FHN AND FHO CAPITATION-ADJUSTMENT RATIOS, MALES

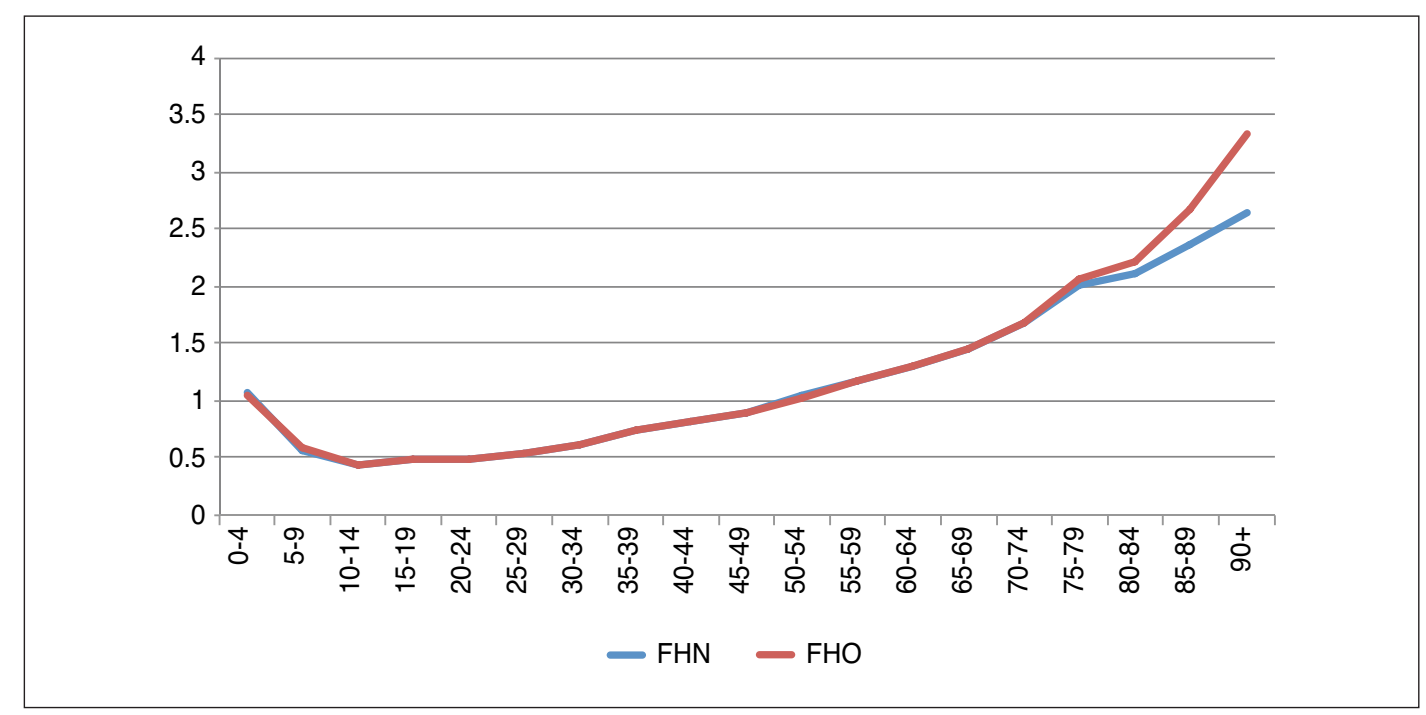

\section{Recent Trends}

Figure 4 presents the number of physicians by primary care payment model from 2004 to 2012. It is a cumulative plot so that the uppermost line, that for "other" category, represents the total number of practicing primary care physicians in the province, and the gap between it and the line below for FHO payment model represents the number in the "other" category. It is important to highlight that all of the models discussed in this paper are voluntary for physicians and they therefore opt into the payment model of their choice.

\section{FIGURE 4: NUMBER OF GPS BY PRIMARY CARE REFORM MODEL, 2004 TO 2012}

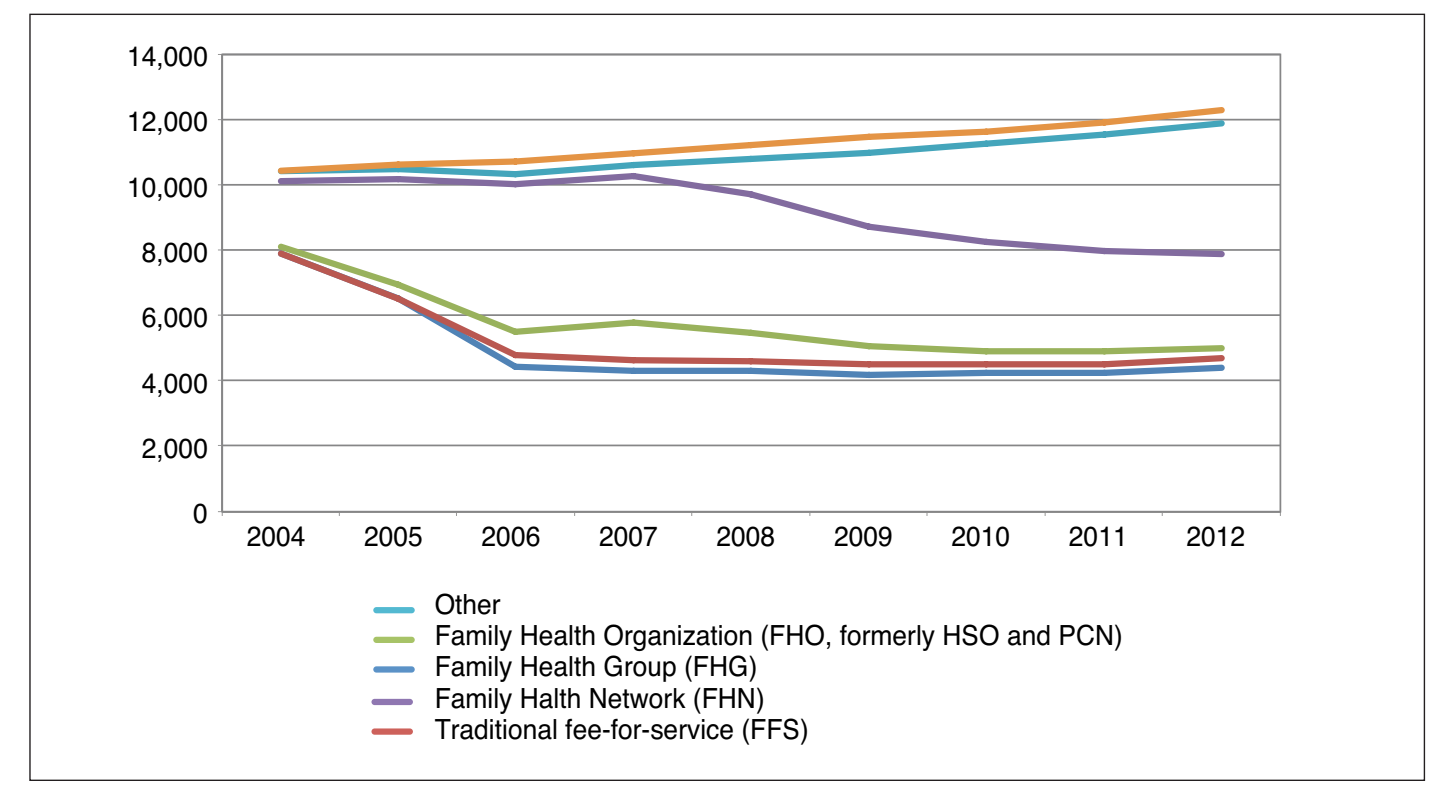

Source: Model counts from: Ontario Ministry of Health and Long-Term Care, "Primary Heath Care in Ontario," Slide 11, November 2013; GP totals from: Ontario Physician Human Resources Data Centre, "Physicians in Ontario by Specialty," https://http://www.ophrdc.org/Public/Report.aspx. 
From 2004 to 2008, the FHG model was the most popular PCR model. However, beginning around 2008, the number of physicians and patients enrolled in FHGs began to decline as many switched to FHOs. In 2011, the number of family physicians in capitation-based blended models (FHNs and FHOs) surpassed those in traditional FFS.

Due to their higher level of remuneration and income predictability relative to FFS, with the latter suggesting that most risk is either alleviated or transferred to patients and/or providers outside the capitated group, capitation-based blended models have been taken up by the younger cohorts of primary care physicians. A factor that may have contributed to the surge in the number of FHOs is a retrospective revenue analysis offered by the ministry to physicians who were pondering switching to a FHO. Recent work by Kantarevic and $\mathrm{Kralj}^{29}$ finds that, among a sample of FHG physicians, the average income gain is substantial and is a strong predictor for whether physicians switched to a FHO or stayed in a FHG. Of course, there is a substantial distribution of income gaps across payment models holding practice structure constant, and some practices would suffer a financial loss if they switched to the FHO model.

With similar trends to the number of physicians in alternative payment models, Figure 5 presents the number of patients enrolled by primary care model, which reached just under 10 million in 2012.

\section{FIGURE 5: NUMBER OF ENROLLED PATIENTS BY PRIMARY CARE REFORM MODEL, 2004 TO 2012}

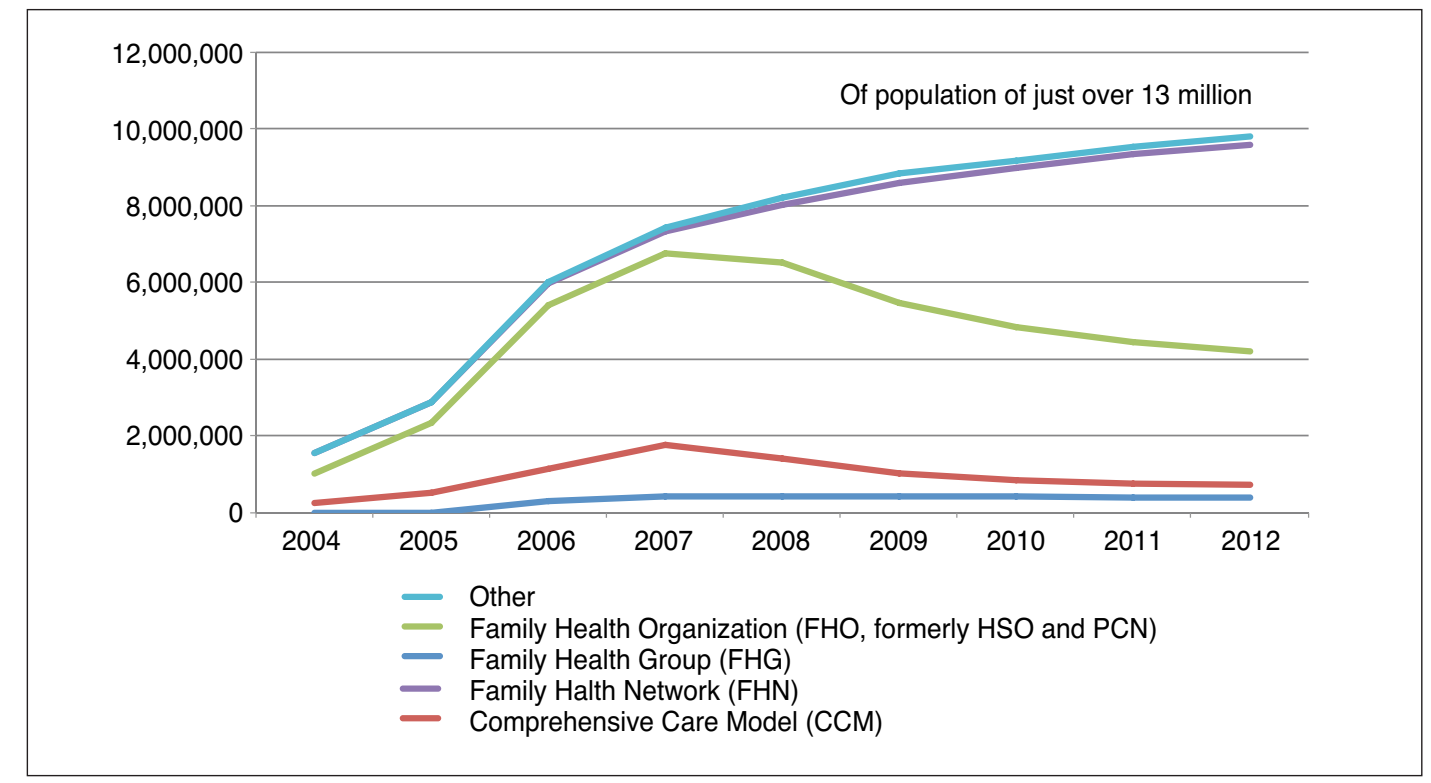

Source: Model counts from Ontario Ministry of Health and Long-Term Care, "Primary Heath Care in Ontario," Slide 12, November 2013.

29 J. Kantarevic and B. Kralj, "Quality and Quantity in Primary Care Mixed Payment Models: Evidence from Family Health Organizations in Ontario," Canadian Journal of Economics 46, 1 (2013). 
As mentioned earlier, these reforms were by no means revenue neutral. In the 2007-08 fiscal year, primary care physicians in FHGs and FHOs billed, on average, between $\$ 376,000$ and $\$ 407,000$, over 25 per cent more than average payments to primary care physicians in traditional FFS. ${ }^{30}$

Since the mid 2000s, the province has made significant investments (or at least increased its expenditures) in primary care. This intentional cost-increasing policy was brought about, at least in part, by mounting access-to-care issues since the number of general practitioners (GPs, sometimes called primary care or family physicians) declined in the 1990s while the number of patients without a regular family doctor increased. Leonard and Sweetman ${ }^{31}$ show that real physician (GP and specialist) taxable earnings declined by about six per cent between 1990 and 1995, but then more than rebounded in the next five years. Then, between somewhere near the bottom of the decline in 1993-94 and 2009-10, Ontario doubled its total nominal payment to all primary care physicians from just over $\$ 1.5$ billion to just over $\$ 3$ billion, ${ }^{32}$ whereas if payments had stayed constant in real dollars per capita, they would have only increased to just over \$2.4 billion. Average per-FTE primary care physician nominal payments in Ontario increased just over 80 per cent during the same time period from $\$ 166,200$ to $\$ 300,100$, or to $\$ 224,946$ in constant 1993 dollars. ${ }^{33}$

Beginning in 2010, mounting fiscal constraints urged the government to begin capping expenditures in various sectors and explore imposing wage freezes on public-sector employees. The most recent and difficult negotiations between the Ontario Medical Association and the Ontario government occurred in 2012 and resulted in a new two-year (as opposed to the normal four-year) agreement that effectively froze total payments to physicians practicing medicine in the province. Grant and Hurley discuss details on this new policy environment. ${ }^{34}$

In April 2009, the ministry froze entry to all patient enrolment models (e.g., FHNs, FHOs, FHGs and CCMs). This cap was lifted soon thereafter for all but FHOs. Effective April 2013, the ministry introduced a "managed entry" of physicians in FHOs and FHNs. The entry is restricted to 40 physicians per month with priority for new graduates and physicians who will be practicing in areas of high need for primary care.

As mentioned earlier, to date the only primary care capitation adjusters adopted have been age and sex. But, as is indicated in the 2012-14 Physician Services Agreement, ${ }^{35}$ the OMA and the ministry are exploring options to develop an "acuity modifier," an adjustment based on the acuity level of patients enrolled. In January 2014, an interim modifier was used to pay physicians in patient enrolment models (i.e., not only capitated) retroactively for the April 2012 - March 2013 year to "adjust payments to primary care physicians who roster acute patients".

${ }^{30}$ S. D. Wooder, "Primary Care Compensation Models," Ontario Medical Assocation, HNHB Board Presentation, April 20, 2011, http://www.hnhblhin.on.ca/uploadedFiles/Public_Community/Board_of_Directors/Board_Meeting/Primary Care Compensation Models - LHIN Presentation - Wooder-FINAL revised.pdf.

31 Phil Leonard and Arthur Sweetman, "Public Health Spending in Canada: Paying the Workers," in Bending the Cost Curve in Health Care, ed. L. Di Matteo and G. Marchildon (Toronto: University of Toronto Press, 2014).

32 D. A. Henry et al., Payments to Ontario Physicians from Ministry of Health and Long-Term Care Sources 1992/93 to 2009/10 ICES Investigative Report (Toronto: Institute for Clinical Evaluative Sciences, 2012), Exhibit 4.3.

33 ibid.

${ }^{34}$ H. Grant, and J. Hurley, "Unhealthy Pressure: How Physician Pay Demands Put the Squeeze on Provincial HealthCare Budgets," The SPP Research Papers 6, 22 (University of Calgary, 2013).

35 Ontario Ministry of Health and Long-Term Care and Ontario Medical Association, 2012 Physician Services Agreement (2012). 
Forty million dollars were allocated across Ontario GPs if they provided the majority of care (at least $50 \%$ ) to patients in the top $20 \%$ of primary health care expenditures defined as services in the FHO capitated basket. ${ }^{36}$ Previous work on adjusting Ontario capitation payments above and beyond age and sex shows that this may reduce the incentive to "cream skim." ${ }^{37}$ More broadly, with only age and sex modifiers, the current model effectively rewards physicians with practices in areas with, on average, low-needs patients, while penalizing those with high-needs patients. These gaps can be appreciable and serve as an important deterrent to establishing or expanding practices in areas where populations have high needs per patient.

The access bonus is also currently under review. The 2012-14 PSA reads: ${ }^{38}$ "The review will consider: (a) the value of negative access bonuses throughout the province; (b) the impact on emergency departments; (c) exemptions for Urgent Care Centres and GP focused practices; and (d) the impact from walk-in clinics."

After-hours requirements were also recently modified for groups with 10 or more physicians. Likely in response to a review of payments to physicians conducted by the Office of the Auditor General of Ontario, ${ }^{39}$ new requirements were introduced as of April 2013 whereby the number of blocks of after-hours services increased from five to seven for groups with 10 to 19 physicians with steps up to a new maximum of 25 blocks for groups with 200 or more physicians. The concern raised by the auditor was that after-hours requirements for groups of five or more physicians were insufficient to meet the demands of patients in large groups with up to 24,000 patients. Also, since these groups may operate out of different locations and afterhours services may be offered in only one location, this may not be convenient for patients who regularly visit other locations.

\section{Other Primary Care Initiatives}

In April 2005, the ministry announced a new integrated and interdisciplinary model: the Family Health Team (FHT). Hutchison et al. describe it as "the provincial government's flagship initiative in primary health care renewal and ... the first explicitly interprofessional primary health care model introduced to Ontario in three decades. ${ }^{40}$ FHTs are teams of core (i.e., physicians and nurses) and interdisciplinary (e.g., in mental health, nutrition, social work) health-care providers that promote comprehensive and interdisciplinary services such as chronic-disease management, counseling, health education, and palliative care. ${ }^{41}$ Note that

\footnotetext{
36 Ontario Ministry of Health and Long-Term Care, OHIP Bulletin 11096, (January 13, 2014, URL: http://www.health.gov.on.ca/en/pro/programs/ohip/bulletins/11000/bul11096.pdf)

37 B. Hutchison et al., "Needs-Adjusted Primary Care Capitation Payment: Development and Comparison of Models," Final Report to the Ontario Ministry of Health and Long-Term Care, September 14, 2006; L. M. Sibley and R. H. Glazier, "Evaluation of the equity of age-sex adjusted primary care capitation payments in Ontario, Canada," Health Policy 104, 2 (2012): 186-192

38 Ontario Ministry of Health and Long-Term Care and Ontario Medical Association, 2012 Physician Services Agreement, Appendix D, Section 6.2.

39 Office of the Auditor General of Ontario, "Funding Alternatives for Family Physicians," 2011 Annual Report of the Office of the Auditor General of Ontario, 2011.

40 Hutchison et al., "Primary health care."

41 Hurley et al., "The Response."
} 
FHTs are not physician-payment models: the FHT model is available to groups of physicians who in turn are in a blended capitation-based or salary-based model (e.g., a FHO). The FHT model provides resources in the form of salary, sessional payment or contractual agreements for allied health-care providers. Currently there are 187 FHTs in Ontario. ${ }^{42}$ An evaluation of FHTs is currently underway. ${ }^{43}$

Announced in 2007, Nurse Practitioner-Led Clinics provide comprehensive primary care including chronic-disease management, and care co-ordination and navigation of the health-care system. These clinics are targeted to unattached patients - that is, individuals who have had difficulty finding a primary care provider and include teams led by nurse practitioners and other healthcare providers such as registered nurses, registered practical nurses, pharmacists, dieticians, social workers and physicians as collaborators. As of May 2012, 22 clinics were open while four other were in development. Once fully operational, these clinics are anticipated to provide care to 40,000 previously unattached patients. ${ }^{44}$

Although Physician Assistants (PAs) have been de facto practicing in the Canadian military for over 50 years and are common in primary care in the U.S., the PA is a relatively new profession in the civilian health-care system in Canada. A PA assists by performing routine tasks otherwise performed by physicians, nurse practitioners and nurses. PAs were introduced in 2007 in Ontario as pilot initiatives in CHCs, hospitals, diabetes clinics and long-term care facilities.

A recent initiative is the announcement of Health Links in December 2012. It is aimed at vertically co-ordinating the care of high-needs patients who represent only five per cent of the population but use two-thirds of the provincial health-care budget. When discharged from hospital, these complex patients, most often seniors, are typically under the care of six or more physicians and get their drugs from three or more pharmacies. The Health Link aims to coordinate care for these patients to avoid unnecessary emergency room visits and hospital readmissions, to alternate level-of-care days in hospital, to reduce wait times for primary care visits, and for referrals to specialists and to home-care services. Nineteen communities piloted this initiative in early 2013, at the time of writing there were 47 Health Links throughout all regions of Ontario ${ }^{45}$ with plans to reach 90 or more by 2015 . Each Health Link was identified by analyzing local natural referral patterns between physicians and hospitals. All Health Links have a co-ordinating partner; for example, a FHT, CHC, or Community Care Access Centre. ${ }^{46}$

42 Government of Ontario website, Family Health Team Locations, http://www.health.gov.on.ca/en/pro/programs/fht/fht_progress.aspx.

43 B. Hutchison and R. H. Glazier, "Ontario's Primary Care Reforms Have Transformed The Local Care Landscape, But A Plan Is Needed For Ongoing Improvement," Health Affairs 32, 4 (2013): 695-703.

44 Government of Ontario, "Nurse Practitioner-Led Clinic Opens In Northwest Toronto," News Release, May 31, 2012, http://news.ontario.ca/mohltc/en/2012/05/nurse-practitioner-led-clinic-opens-in-northwest-toronto.html.

45 Government of Ontario website, "Transforming Ontario's Health Care System - Community Health Links provide coordinated, efficient and effective care to patients with complex needs," http://www.health.gov.on.ca/en/pro/programs/transformation/community.aspx.

46 Government of Ontario, “About Health Links,” Archived Backgrounder, 2012, http://news.ontario.ca/mohltc/en/2012/12/about-health-links.html; A. Silversides and A. Laupacis, "Health Links: Ontario's bid to provide more efficient and effective care for its sickest citizens," HealthyDebate.ca, February 28, 2013, http://healthydebate.ca/2013/02/topic/innovation/the-ontario-health-links-initiative-what-is-it. 
Several other primary care initiatives and enhancements have been introduced in Ontario or have been underway for some time. For example, Health Care Connect is a program for which people without a primary care provider can sign up, and it attempts to link unattached patients to providers; priority is assigned to people with the highest need. The Canadian Health Services Research Foundation's Casebook of Primary Healthcare Innovations features a number of interesting initiatives across the country. ${ }^{47}$

\section{Interdisciplinary Care}

Currently, there are approximately 300 groups or centres that provide interdisciplinary ${ }^{48}$ primary care in Ontario: 75 Community Health Centres, 187 Family Health Teams who alone serve approximately 3 million patients, 26 Nurse Practitioner-Led Clinics, and 10 Aboriginal Health Access Centres. Physician-payment models such as FHGs, FHNs and FHOs have had limited ability to provide interdisciplinary care; for example, FHNs and FHOs not affiliated with a FHT can hire one or more nurse practitioners ${ }^{49}$ to provide services within their scope of practice or can hire a nurse for the provision of their THAS services. Other examples of allied professionals being integrated in a primary care physician team exist, but they appear to be few and isolated, ad hoc initiatives ${ }^{50}$ Other primary care reform models (e.g., GHC, RNPGAs, SEAMO) have arrangements in place whereby the ministry pays salaries for allied health professionals who are providing services to patients of the group/centre.

The province of Ontario has been expanding team-based care, particularly with its expenditures in funding to FHTs, motivated by the idea that primary care should be increasingly centred around health promotion and chronic-disease management and that all providers on the team should practice at the upper end of their scope of practice. Efficiencies are anticipated since patients with minor health problems (e.g., a common cold) or more specific health problems (e.g., eating disorder) can be seen by the lowest-cost qualified practitioner, particularly since many health-care needs do not need to be addressed by a physician. In conjunction with Health Quality Ontario, the Ontario government has introduced a performance-monitoring initiative, the Quality Improvement Plan, whereby health-care providing organizations are required to annually fill in and submit a template with predefined metrics. The government first imposed this requirement on hospitals and, effective April 1, 2013, has generated a primary-carespecific template and extended this reporting requirement to the province's 300 interprofessional groups/centres who must submit data on predefined metrics (e.g., access to primary care when needed by patients, timely follow-up appointment post-discharge, and patient-centred primary care delivery care based on patient feedback). ${ }^{5 I}$

47 Change in Primary Healthcare, Casebook of Primary Healthcare Innovations (Ottawa: Canadian Health Services Research Foundation, 2010)

48 In the health-services-research literature, a primary care team - which includes allied health professionals (e.g., registered nurses, dieticians, social workers and pharmacists) - can be referred to as "interdisciplinary," "multidisciplinary" or "interprofessional."

49 These nurse practitioners may be funded by the ministry in special cases (e.g., if the group applies for a grant).

50 For example: the Hamilton HSO Mental Health and Nutrition Program, or specialized pilots funded by the Primary Health Care Transition Fund in the 2002-2006 period.

51 Government of Ontario website, "Quality Improvement Plans,"

http://www.health.gov.on.ca/en/pro/programs/ecfa/legislation/qi_primary.aspx. 


\section{HAVE INVESTMENTS IN PRIMARY CARE PAID OFF?}

The majority of the incremental $\$ 1.5$ billion recently invested (or expended) by Ontario in primary care has been devoted to alternative primary care models while total payment to traditional FFS have remained relatively stable. ${ }^{52}$ Both sides of this financial outlay picture are of importance. Clearly, substantial resources are being devoted to alternative models of remuneration. However, the stability of total payments to traditional FFS is itself interesting since the number of physicians in this category fell from about 5,100 to around 3,600 from 2005 to 2009 while, as will be seen, the numbers in alternative models, which tend to be better remunerated, have been increasing. Overall, individual physician billings/remuneration has been increasing at a faster rate than inflation. Leonard and Sweetman ${ }^{53}$ show that taxable income of physicians has also been rising much more rapidly than that in the non-health workforce. We now provide highlights from the literature in regards to some of the goals that were established for primary care, especially access to and quality of care. These findings are, however, preliminary both in the sense that relatively few analyses have been undertaken with most of these focusing on narrow issues, and also in that the new "system" is not yet stable and these findings are best interpreted as short-run outcomes. Timing is a particularly important issue since there have been numerous changes involving a complex array of relatively modest bonuses, incentives, premiums and related aspects of the new models. It may well take some time, and investments in information technology and associated management practices, for the full response to these changes to be observed.

Although Ontario has experimented with various primary care physician-payment models, these models are very similar in regards to many payment elements and characteristics: for example, all models are characterized by enrolment-based practices ${ }^{54}$ after-hours serviceprovision requirements, comprehensive-care provision, incentives and special payments. The key difference between the most common models are:

- The main payment component for FHOs and FHNs is capitation, while for FHGs and CCMs it remains FFS. This main capitation payment to FHOs and FHNs is limited to services that must be both in the capitated basket and provided to enrolled patients (this amounts to approximately 60-70 per cent of per-FHN/FHO physician payment). Services to un-enrolled patients or services outside of the basket are still paid FFS.

- The CCM model is a solo model, whereas the remaining models are group-based requiring at least three physicians.

\footnotetext{
52 Henry et al., "Payments to Ontario".

53 Leonard and Sweetman, "Public Health Spending."

54 As opposed to practices that may be defined geographically, whereby a primary care physician is responsible for the care of all residents of a defined geographical area.
} 


\section{Access to Care}

Between 2003 and 2010, over 2 million previously unattached patients, equivalent to about 15 per cent of the total population, became attached to a family physician. ${ }^{55}$ Despite this increment to the number of patients rostered, the Office of the Auditor General ${ }^{56}$ notes that, when surveyed, many patients appear to be unaware of their enrolment. Moreover, Glazier and colleagues $^{57}$ argue that "having a doctor does not mean a patient can see that doctor in a timely way" and that, although the proportion of patients attached to a primary care physician increased, primary care reform has not been successful in decreasing emergency department (ED) use. Future research should aim to further unpack ED use so to analyze the relationship between avoidable visits made to EDs, patient characteristics and characteristics of the patient's primary care physician. ${ }^{58}$ However, Glazier et al. ${ }^{59}$ point out the methodological difficulty in defining an avoidable ED visit. Kralj and Kantarevic ${ }^{60}$ use semi-urgent and nonurgent ED visits as a proxy for avoidable ED visits and find a reduction in their proportion to total ED visits from 0.57 to 0.45 between 2003 and 2009. This is coupled with an increase in total primary care services provided during after hours from 1 million to 3.5 million. On the contrary, after adjusting for patients' individual morbidity burden and calculating the proportion of actual to expected ED visits, Glazier et al. ${ }^{61}$ find that patients in FHNs and FHOs have higher ED use than FFS patients; the lowest actual-to-expected-ED-visit ratio being held by patients receiving services from CHCs.

When comparing the number of services provided, visits made, and distinct patients seen by physicians in the traditional FFS model to physicians in FHGs, Kantarevic and colleagues ${ }^{62}$ find that FHG physicians provide 9.4 per cent more services, particularly on days when they offer after-hours services. The authors also find that FHG physicians refer to specialists less than FFS physicians despite caring for slightly more complex patients. FHOs, on the other hand, provide six to seven per cent fewer services. ${ }^{63}$ Of course, interpretation can be difficult in these contexts. The gap between FHG and FHO reflects the theoretical prediction that FFS payment models, such as FHGs, will over-provide. FHGs and traditional FFS physicians are

55 B. Kralj and J. Kantarevic, "Primary Care in Ontario: Reforms, Investments and Achievements," Ontario Medical Review (February 2012): 18-24.

56 Office of the Auditor General of Ontario, "Funding Alternatives."

57 R. H. Glazier et al., "All the Right Intentions but Few of the Desired Results: Lessons on Access to Primary Care from Ontario's Patient Enrolment Models," HealthCare Quarterly 15, 3 (2012): 19.

58 From a different perspective, future research should also focus on unpacking ED use to assess whether chronic-care management and preventive-care services provided by GPs are successful in avoiding adverse events and, consequently, ED use.

59 R. H. Glazier, B.M. Zagorski and J. Rayner, "Comparison of Primary Care Models in Ontario by Demographics, Case Mix and Emergency Department Use, 2008/09 to 2009/10," ICES Investigative Report (Toronto: Institute for Clinical Evaluative Sciences, 2012).

60 Kralj and Kantarevic, "Primary Care in Ontario."

61 Glazier, Zagorski and Rayner, "Comparison."

62 J. Kantarevic, B. Kralj and D. Weinkauf, "Enhanced fee-for-service model and physician productivity: evidence from Family Health Groups in Ontario," Journal of Health Economics 30, 1 (2011): 99-111.

63 Kantarevic and Kralj, "Quality and Quantity." 
both paid prevalently or in whole via FFS (although the FHG also has access to bonuses and incentives), but the FHGs are required to provide after-hours care and are paid a premium for doing so. While these findings suggest that FHG physicians are not "undoing" the extra hours expected of them, it's not clear what portion of the gap is because of the form, as opposed to the level of remuneration. Self-selection is also an important issue that some authors seek to address, typically using propensity score matching that conditions on observable characteristics but does not take into account any factors not observed in the data. The administrative data have a limited range of characteristics, but the one key variable used by some researchers that makes this approach plausible is an estimate of the physician-specific difference in income under the alternative payment models using the previous year's billing pattern. If remuneration (holding practice style at the pre-change norm) is a key driver of model choice, then this variable makes matching a plausible approach to generating a counterfactual in order to estimate the causal impact of payment method on physician behaviour.

It is worth noting that the "intended" alternative practice model and the "delivered" one need not correspond exactly. For example, in one study, a random telephone survey contacting primary care physicians' offices after hours found many physicians providing no or few instructions for their patients on to how to access the appropriate health-care provider (e.g., after-hours clinic, THAS, Telehealth Ontario, walk-in clinic) based on their acuity level. ${ }^{64}$ The Ontario government has since made efforts to publicize the multitude of health-care options available to patients when they have a semi-urgent or non-urgent health-care problem during after hours. More generally, in his 2011 report, the auditor general suggested that there has been insufficient verification that the contracted service elements associated with the new primary care models have actually been undertaken.

\section{Preventive-Care and Chronic-Care Management}

As a proxy for analyzing the quality of care, many health-economics studies analyze the rate with which selected services (e.g., preventive-care and chronic-care management, which are object of targeted performance-based incentives) are being provided to eligible patients. In the context of the pay-for-performance literature, some studies have looked at the impact Ontario PCR models may have had on the provision of these targeted services: Kiran et al. ${ }^{65}$ find that patients enrolled to a physician in blended capitation received 25 per cent more recommended diabetes tests in the 2006-2008 period than before it, while patients of the same physicians, but not formally enrolled, received significantly fewer tests. However, most of the physicians presented the higher rates as early as 1998; that is, prior to the introduction of most capitated PCR models suggesting important selection into the new models. The same set of diabetes services is the object of another recent study in which the authors also find physicians who switched to a blended capitation model present higher rates of compliance. ${ }^{66}$ In other work, the

\footnotetext{
${ }^{64}$ M. Howard and G.E. Randall, "After-Hours Information Given by Telephone by Family Physicians in Ontario," HealthCare Policy 5, 2 (2009): 106-115.

65 Tara Kiran et al., "The Relationship Between Financial Incentives and Quality of Diabetes Care in Ontario, Canada," Diabetes Care 35, 5 (2012): 1038-1046.

66 J. Kantarevic and B. Kralj, "Link between pay for performance incentives and physician payment mechanisms: Evidence from the diabetes management incentive in Ontario," Health Economics 22 (2013): 1417-1439.
} 
same authors find that FHO physicians are seven to 11 per cent more likely to achieve targets for preventive care (flu shots for seniors, mammograms, Pap smears, childhood immunizations, and colorectal-cancer screening) than are FHG physicians.$^{67} \mathrm{Li}$ et al. ${ }^{68}$ find modest difference, and in some cases not statistically significant differences, in the rate of provision of the same preventive-care services between GPs in a PCR model compared to traditional FFS. Overall, there is insufficient evidence to incontrovertibly conclude whether such investments have yielded the cost-effective benefits that were anticipated.

\section{Physician Models and Billings}

In terms of physician payments, Henry et al.$^{69}$ illustrate the change in the main sources of income relative to the most popular payment models between 2005-06 and 2009-10.

FIGURE 6: TOTAL PAYMENTS TO PRIMARY CARE PHYSICIANS BY PAYMENT TYPE AND PRIMARY CARE REFORM MODEL

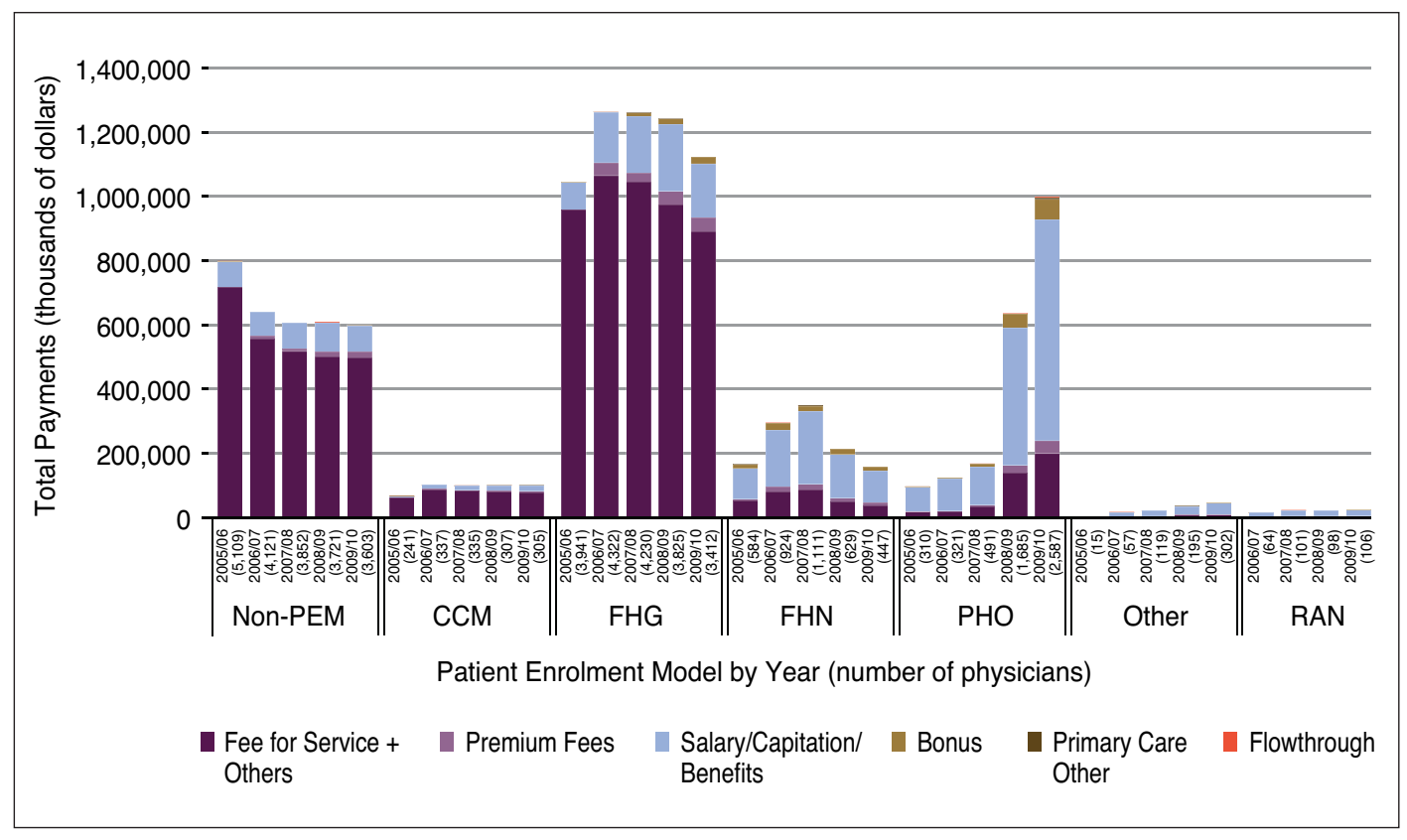

Source: D. A. Henry et al., Payments to Ontario Physicians from Ministry of Health and Long-Term Care Sources 1992/93 to 2009/10 ICES Investigative Report (Toronto: Institute for Clinical Evaluative Sciences, 2012): Exhibit 4.5. With permission from ICES.

\footnotetext{
67 Kantarevic and Kralj, "Quality and Quantity."

${ }^{68}$ Li et al., "Physician Response."

${ }^{69}$ Henry et al., "Payments to Ontario."
} 


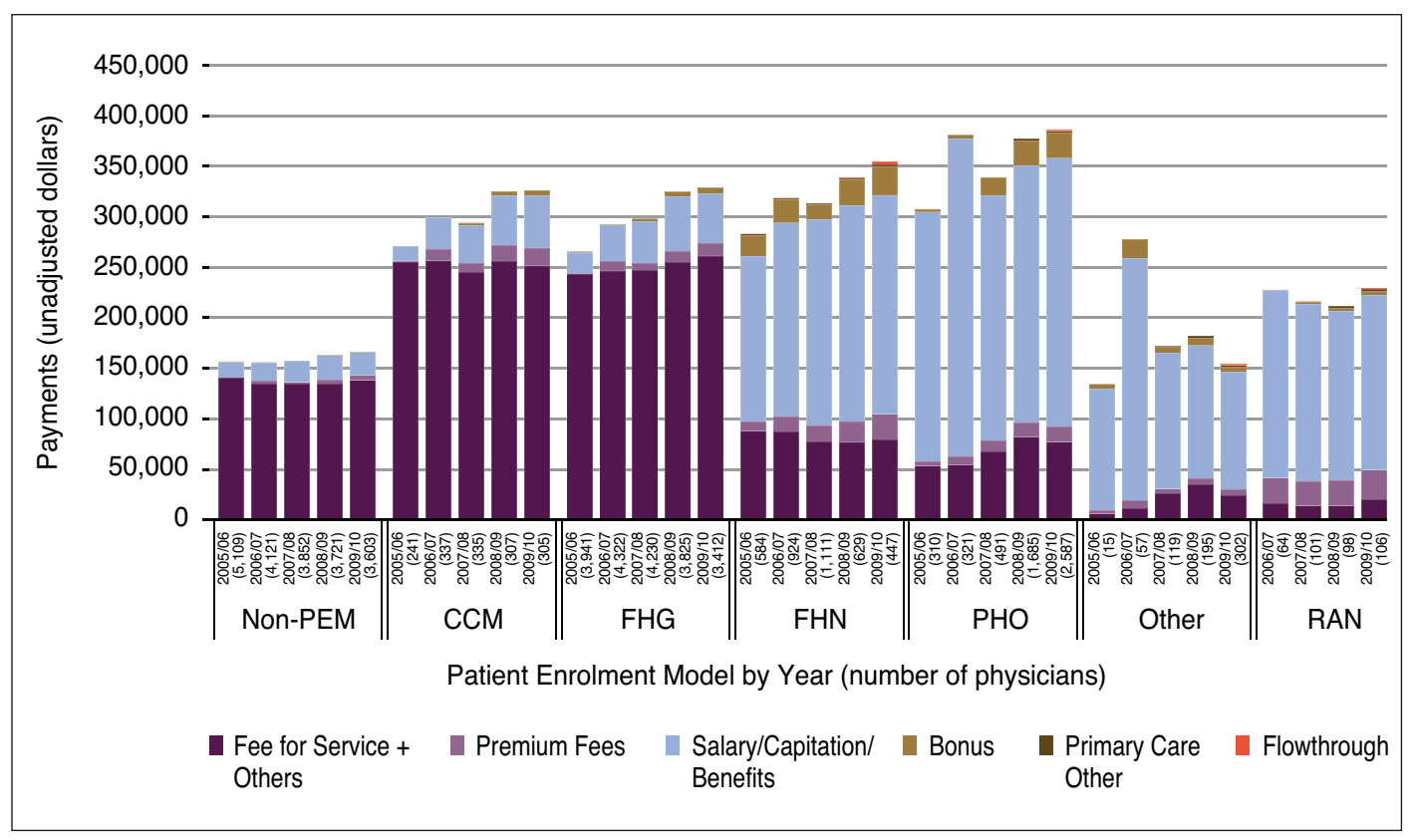

Source: D. A. Henry et al., Payments to Ontario Physicians from Ministry of Health and Long-Term Care Sources 1992/93 to 2009/10 ICES Investigative Report (Toronto: Institute for Clinical Evaluative Sciences, 2012): Exhibit 4.4. With permission from ICES.

It is evident from the above figures that substantial recent expenditures have been devoted to funding FHOs, many of which are former FHGs that switched to the FHO model under the expectation of higher and more predictable income levels. Figure 7 shows how the proportion of capitation payments is higher for FHOs, at around 70 per cent, compared to FHNs whose proportion appears to be around 62 per cent.

McGuire $^{70}$ argues for blended capitation and, as mentioned, he suggests that the FFS component should be somewhat smaller than variable costs given physicians' preferences to serve their patients well (as well as patient demand and other factors pushing towards excess service supply). However, he estimates that fixed costs are only about 30 per cent of total payments. He admits that the ratio of fixed to variable costs is not well understood, and it might be quite different in Canada compared to his U.S. experience, but the difference from the Ontario experience where the FFS component for in-basket service elements is only 15 per cent (formerly 10 per cent) is notable. Of course, Ontario's practices are blended on multiple dimensions as discussed above and no formal analysis has been undertaken regarding the optimal relative size of the blended components in as complex a funding environment as that observed here. Undoubtedly, blending on one dimension - in the form of fee codes separated into a "capitated basket" and FFS codes outside that basket - reduce the financial risk faced by the practice and allow less blending on the payment dimension within the capitated basket since the practice can bear more risk on that dimension.

70 McGuire, "Physician Agency." 
The incentive associated with a capitation formula that adjusts only for the age and sex of the patient is for a physician to "cream skim" by tending to roster patients who, compared to their counterparts of the same sex and age, are healthier. One study ${ }^{71}$ points to little evidence of cream skimming by capitated Ontario physicians, while another recent study ${ }^{72}$ found that patients in Ontario were discriminated against based on their health and socioeconomic status, regardless of the physician payment model.

Although age and sex alone may be preferred by physicians because they provide greater stability in payments, a patient's health can change dramatically, and with it the frequency with which patents will seek primary care services, and this may not "average out" in a modestsized practice. More importantly, there may be systematic differences across practices; for example, those located in particular geographic locations may have much higher- or lowerneeds patients. A morbidity-related adjuster would enable hard-to-roster patients with high needs to be enrolled by a capitated physician. Ontario's Health Care Connect program is a good example in this regard: Between 2009 and 2013, almost 240,000 patients were able to find a family doctor through the program. ${ }^{73}$ However, despite priority being given to highneeds patients in the Health Care Connect program, the proportion of high-needs patients that were successfully matched to a GP is slightly lower than the proportion of matched patients with relatively lower needs. ${ }^{74}$

Given the context, it is difficult for research and evaluation to disentangle the effect of many of the individual elements of primary care models. Rostering in itself is a powerful tool, but the Ontario agreements also incorporate several distinct contract elements in conjunction with rostering (even in the solo CCM model, rostering has been introduced alongside some small comprehensive-care payments and some small performance-based incentives). It can be argued that, in the current context where there is an undersupply of physicians, the incentives to oversupply services is reduced, and the ministry could have accomplished almost all of its goals without introducing capitation - although some studies ${ }^{75}$ conclude much the opposite and find a small but nontrivial reduction in services associated with capitation. However, the greatest benefits of capitation may be in the future, as it offers scope for improved management in that it addresses the excess supply-of-service issue discussed earlier, which may become pressing if the supply of physicians relative to "need" moves from shortage to surplus.

\footnotetext{
71 Kantarevic and Kralj, "Link between."

72 Michelle E. Olah, Gregory Gaisano and Stephen W. Hwang, "The effect of socioeconomic status on access to primary care: an audit study," Canadian Medical Association Journal 185, 6 (2013): E263-E269.

73 Government of Ontario website, "Health Care Connect - Program Results," http://www.health.gov.on.ca/en/ms/healthcareconnect/public/results.aspx.

74 ibid.

75 For example: Kantarevic and Kralj, "Quality and Quantity."
} 
Turning to pay-for-performance, many of the current incentives appear to be too small to encourage costly action, and the desired goals could probably be executed (more) effectively (in conjunction with) with education. Beneficially, Kantarevic and Kralj find that: "FHO physicians have about $3 \%$ fewer referrals per rostered patient than the comparable FHG physicians." ${ }^{176}$ While this may seem counterintuitive given the incentives built into capitation models, if it is not entirely the result of selection into payment models by physicians, it is a welcome result. On the other hand, Liddy et al. ${ }^{77}$ find, in accordance with theory, that FFS physicians refer less than capitated physicians and among the latter, those in an interdisciplinary model refer less than those in a non-interdisciplinary model.

Satisfaction, as surveyed by Green et al. ${ }^{78}$ was found to be higher among physicians when in a non-FFS payment (FHN, CHC or HSO) model compared to an FFS payment (i.e., FFS or FHG) model. However, it is unclear if this results from the higher remuneration levels of the alternative payment models, and/or the structure of the models themselves (or perhaps it is a residual of the self-selection into the new arrangements).

\section{General Evaluation Considerations}

A key relevant issue is that we appear to be in a new era where there is an increased need for active management by the ministry. In the past, the ministry has been largely hands off: it appears to have signed contracts, but then has not checked to see if the contracts were fulfilled. The argument is that the payer, as a representative of the patient and the taxpayer, needs to be actively engaged. A related issue is the "footprint" that the primary care models produce in the health-care system. In particular, there is not a lot of evidence on any impacts on downstream costs (e.g., prescription drugs, care provided by specialists, hospital costs, and use of diagnostic tests).

\section{CONCLUSIONS}

Significant primary care expenditures have been made by the Ontario government in recent years; among other areas, many of these funds have been devoted to interdisciplinary care (salaries for allied health professionals) and capitation payments to physicians. Empirical studies using recent Ontario administrative data have some mixed and conflicting results in terms of access, "quality,"79 and satisfaction; for example, in regards to the effect of capitation on rates of referral or the effect of capitation on reducing ED visits. Additionally, these findings are preliminary both in the sense that relatively few analyses have been undertaken, with most of these focusing on narrow issues, and also in that the new "system" is not yet stable and

\footnotetext{
76 ibid., 210.

77 C. Liddy et al., "What is the impact of primary care model type on specialist referral rates? A cross-sectional study," BMC Family Practice 15, 22 (2014).

${ }^{78}$ M. E. Green et al., "Financial and work satisfaction: impacts of participation in primary care reform on physicians in Ontario," HealthCare Policy 5, 2 (2009): e161-176.

${ }^{79}$ For example, measured by a proxy: the rate of preventive-care- and chronic-care-management service provision.
} 
these findings are best interpreted as short-run outcomes (and the timing of various studies may explain some of the conflicting outcomes). It may well take some time, and further investments in information technology and associated management practices, for the full response to these changes to be observed. Timing is a particularly important issue since there have been numerous changes involving a complex array of relatively modest bonuses, incentives, premiums and related aspects of the new models alongside capitation. Consequently, we see a variety of studies each with a different design, emphasis and outcome measure, making it challenging to compare results. We conclude that it is difficult for research and evaluation to disentangle the effect of many of the individual contract elements (e.g., rostering, capitation, incentives, after-hours service requirements) of Ontario's primary care models since many were introduced simultaneously.

Given that the recent past has seen a shortage of physicians in Ontario, it can be argued that the Ontario government could have accomplished almost all of its goals without introducing capitation. On the other hand, capitation offers scope for improved management going forward since it addresses the excess supply-of-service issue, which may become pressing if the supply of physicians relative to "need" moves from shortage to surplus. We find traditional FFS (alone) to be a sub-optimal payment method and we concur with the grand majority of the literature that a blended payment method, based on fee-for-service, incentives and morbidityadjusted capitation payments, is preferable. However, no formal analysis has been undertaken regarding the optimal relative sizes of the blended components in as complex a funding environment as that observed here. Also, we need to think clearly about how to use capitation to attain a set of desired and pre-defined goals.

Although capitation payments adjusted by age and sex alone may be preferred by physicians, because they provide greater stability in payments, a patient's health can change dramatically and, with it, the frequency with which patients will be seeking primary care services, and this may not "average out" in a modest-sized practice. More importantly, there may be systematic differences across practices; for example, those located in particular geographic locations may have much higher- or lower-needs patients. A morbidity-related adjuster would enable hard-toroster patients with high needs to be enrolled by a capitated physician. There are efficiency and fairness issues at play in that, without a morbidity-adjusted capitation payment, physicians would not want to establish a capitated practice in a high-needs area.

Patient rostering has enormous rhetorical and political value in that it clarifies the one-to-one correspondence between the patient and the practitioner or practice, and thus identifies which physicians are "responsible" for which patients in order to proactively provide preventive services and manage chronic conditions. However, when surveyed, many patients appear to be unaware that they are rostered. It remains to be seen if it is important for patients to be aware of the relationship for it to be worthwhile for the province.

In terms of Ontario's promotion of teamwork, it is unclear whether the groups of physicians clustered into "teams" for the purposes of joining an FHG or FHO, actually function well as a team and whether providers desire this payment model. The associated co-ordination costs of teamwork remain unknown and they are also likely to change as information technology is not only installed, but actually used. There is little evidence on the effectiveness of interdisciplinary teams, although an evaluation of FHTs appears to be currently underway. 
Ontario has introduced several initiatives and a very large number of relatively modest pay-forperformance bonuses/incentives. Some of these seem to have worked well (e.g., diabetesmanagement payments) and others less so (e.g., THAS and preventive-care contact incentives have been recently discontinued; the preventive-care bonuses appear to have had minimal effects on physician behaviour). Although, as mentioned above, we must re-evaluate later to allow primary care practices time to adjust.

Ontario's experience appears to be one of learning through trials, successes, and some initiatives that have not operated as expected. That is, by making ongoing changes in light of feedback, followed by the re-adjustment of expectations and goals "it takes time to turn a large ship around." One crucial factor for future success appears to be an active management role from the ministry in assessing primary-care-groups' performance. Also, a better understanding of the "footprint" that the primary care models produce in the health-care system is clearly needed. In particular, there is not a lot of evidence on the existence and/or magnitude of any impacts on downstream costs (e.g., prescription drugs, care provided by specialists, hospital costs, and the use of diagnostic tests). Primary care reform in Ontario remains an ongoing endeavour. 


\section{APPENDIX 1: CHRONOLOGY OF MAJOR PRIMARY CARE PAYMENT MODELS AND GROUPS IN ONTARIO, 1963 TO PRESENT ${ }^{80}$}

\begin{tabular}{|c|c|c|c|c|c|}
\hline $\begin{array}{l}\text { Start } \\
\text { Date }\end{array}$ & $\begin{array}{l}\text { Model / } \\
\text { Group Name }\end{array}$ & Location & Main Payment Elements ${ }^{81}$ & $\begin{array}{l}\text { Group } \\
\text { Requirement }\end{array}$ & Details \\
\hline 1963 & $\begin{array}{l}\text { Group Health } \\
\text { Centre (GHC) }\end{array}$ & Sault Ste. Marie & $\begin{array}{l}\text { - Capitation } \\
\text { - Bonuses and incentives }\end{array}$ & Group & \\
\hline $\begin{array}{l}\text { July 1, } \\
1966\end{array}$ & FFS (FFS) & Ontario & $\begin{array}{l}\text { "Traditional" FFS: } 100 \text { per cent of fees } \\
\text { as posted in Ontario Schedule of } \\
\text { Benefits }\end{array}$ & Solo & $\begin{array}{l}\text { - As of April 2008: some small } \\
\text { incentives }\end{array}$ \\
\hline 1970s & $\begin{array}{l}\text { Community } \\
\text { Health Centres } \\
\text { (CHCs) }\end{array}$ & $\begin{array}{l}75 \text { CHCs and } 28 \\
\text { satellites across } \\
\text { Ontario }\end{array}$ & $\begin{array}{l}\text { - Salary (physicians are employees of the } \\
\mathrm{CHC} \text { ) }\end{array}$ & Group & - After-hours requirements \\
\hline 1973 & $\begin{array}{l}\text { Health Service } \\
\text { Organizations } \\
\text { (HSOs) }\end{array}$ & Ontario & $\begin{array}{l}\text { - Capitation for enrolled patients } \\
\text { (outside-use penalties) for core } \\
\text { services and FFS for other services } \\
\text { - Capped FFS for core services to non- } \\
\text { enrolled patients } \\
\text { - Incentives and bonuses } \\
\text { - Customized program funding }\end{array}$ & $\begin{array}{l}\text { Groups and small } \\
\text { number of solo } \\
\text { physicians }\end{array}$ & $\begin{array}{l}\text { - No after-hours requirements } \\
\text { - Enrolment requirements } \\
\text { - Harmonized into the FHO on } \\
\text { Nov. } 1,2006^{82}\end{array}$ \\
\hline 1990 & $\begin{array}{l}\text { Comprehensive } \\
\text { Health } \\
\text { Organizations } \\
\text { (CHOs) }\end{array}$ & Ontario & $\begin{array}{l}\text { Global funding for the organization, } \\
\text { then slowly move to capitation }\end{array}$ & Group & - Was never implemented \\
\hline $\begin{array}{l}\text { July } 1, \\
1994\end{array}$ & $\begin{array}{l}\text { Southeastern } \\
\text { Ontario } \\
\text { Academic } \\
\text { Medical } \\
\text { Organization } \\
\text { (SEAMO) }\end{array}$ & Kingston & - Same as FHNs & Group & - Same as FHNs \\
\hline 1996 & $\begin{array}{l}\text { Community } \\
\text { Sponsored } \\
\text { Contracts (CSCs) }\end{array}$ & Rural Ontario & $\begin{array}{l}\text { - Salary } \\
\text { - Incentives }\end{array}$ & Solo or groups & $\begin{array}{l}\text { - Harmonized into the RNPGA } \\
\text { on April 1,2004 }\end{array}$ \\
\hline 1998 & $\begin{array}{l}\text { Northern Group } \\
\text { Funding Plan } \\
\text { (NGFP) }\end{array}$ & Northern Ontario & $\begin{array}{l}\text { - Salary } \\
\cdot \text { Incentives }\end{array}$ & Groups & $\begin{array}{l}\text { - Harmonized into the RNPGA } \\
\text { on April 1, } 2004\end{array}$ \\
\hline
\end{tabular}

${ }^{80}$ Please note that the above table is not exhaustive as other smaller/local primary care reform models have been excluded: Inner City Health Associates (ICHA), St. Joseph's Family Practice Unit, Weeneebayko Area Health Authority (WAHA), Toronto Palliative Care Agreement (TPCA), and the Community Sponsored Agreement Blended Salary Model.

${ }^{81}$ For many models, some payment elements were not introduced at the time the model was introduced, but were introduced later (for example, FHOs, FHGs and CCMs became eligible for a cumulative preventive-care bonus for flu shots to seniors in April 2007). Also, some payment elements have been removed (for example, effective Jan. 1, 2013, payments to physicians for being on-call for the Telephone Health Advisory Service were terminated as this service is no longer provided), while others have been modified (for example, the after-hours premium was initially equal to 10 per cent of the value of the service provided, increasing to 15 per cent in April 2005 and then to 20 per cent in April 2006). For existing models, we list the current payment elements; for models no longer available (e.g., HSOs, PCNs), we list the payment elements that were available at the time the model was discontinued.

82 The FHO has a minimum requirement of three physicians in the group, but existing HSOs composed of solo physicians were grandfathered in 2006 and were thus not required to meet this minimum. 


\section{APPENDIX 1: CHRONOLOGY OF MAJOR PRIMARY CARE PAYMENT MODELS AND GROUPS IN ONTARIO, 1963 TO PRESENT (cont'd)}

\begin{tabular}{|c|c|c|c|c|c|}
\hline $\begin{array}{l}\text { Start } \\
\text { Date }\end{array}$ & $\begin{array}{l}\text { Model / } \\
\text { Group Name }\end{array}$ & Location & Main Payment Elements & $\begin{array}{l}\text { Group } \\
\text { Requirement }\end{array}$ & Details \\
\hline 1999 & $\begin{array}{l}\text { Primary Care } \\
\text { Networks (PCNs) }\end{array}$ & Ontario & $\begin{array}{l}\text { - Capitation for enrolled patients } \\
\text { (outside-use penalties) for core } \\
\text { services and FFS for other services } \\
\text { - Comprehensive-care capitation for } \\
\text { enrolled patients } \\
\text { - Capped FFS for core services to non- } \\
\text { enrolled patients } \\
\text { - Incentives and bonuses } \\
\text { - After-hours premium }\end{array}$ & $\begin{array}{l}\text { Groups of seven or } \\
\text { more physicians }\end{array}$ & $\begin{array}{l}\text { - After-hours requirements } \\
\text { - Enrolment requirements } \\
\text { - Harmonized into the FHO on } \\
\text { Nov. } 1,2006\end{array}$ \\
\hline $\begin{array}{l}\text { Dec. 1, } \\
2002^{83}\end{array}$ & $\begin{array}{l}\text { Family Health } \\
\text { Networks (FHNs) }\end{array}$ & Ontario & $\begin{array}{l}\text { - Capitation for enrolled patients plus } \\
\text { shadow-billing premium and access } \\
\text { bonus for core services and FFS for } \\
\text { other services } \\
\text { - Comprehensive-care capitation for } \\
\text { enrolled patients } \\
\text { - Capped FFS for core services to non- } \\
\text { enrolled patients } \\
\text { - Incentives and bonuses } \\
\text { - After-hours premium }\end{array}$ & $\begin{array}{l}\text { Groups of three or } \\
\text { more physicians }{ }^{84}\end{array}$ & $\begin{array}{l}\text { - After-hours requirements } \\
\text { - Enrolment requirement of } \\
2,400,3,200 \text { or } 4,000 \\
\text { patients for groups of three, } \\
\text { four or five physicians, } \\
\text { respectively } \\
\text { - Can hire a FHN-contract } \\
\text { physician or a nurse } \\
\text { practitioner }\end{array}$ \\
\hline $\begin{array}{l}\text { July 1, } \\
2003\end{array}$ & $\begin{array}{l}\text { Family Health } \\
\text { Groups (FHGs) }\end{array}$ & Ontario & $\begin{array}{l}\text { - FFS as usual } \\
\text { - Comprehensive-care capitation and } \\
\text { comprehensive-care premium for } \\
\text { enrolled patients } \\
\text { - Incentives and bonuses } \\
\text { - After-hours premium }\end{array}$ & $\begin{array}{l}\text { Groups of three or } \\
\text { more physicians }\end{array}$ & $\begin{array}{l}\text { - After-hours requirements } \\
\text { - Enrolment is optional, though } \\
\text { eligibility for many incentives } \\
\text { based on services to enrolled } \\
\text { patients }\end{array}$ \\
\hline $\begin{array}{l}\text { April 1, } \\
2004\end{array}$ & $\begin{array}{l}\text { Rural and } \\
\text { Northern } \\
\text { Physician Group } \\
\text { Agreement } \\
\text { (RNPGA) }\end{array}$ & $\begin{array}{l}\text { Rural or } \\
\text { Northern Ontario }\end{array}$ & $\begin{array}{l}\text { - Base remuneration (salary) } \\
\text { - Shadow-billing premium } \\
\text { - Comprehensive-care capitation for } \\
\text { - enrolled patients } \\
\text { - Incentives and bonuses } \\
\text { - After-hours premium }\end{array}$ & Solo or groups & $\begin{array}{l}\text { - After-hours requirements } \\
\text { - Enrolment is optional, though } \\
\text { eligibility for many incentives } \\
\text { based on services to enrolled } \\
\text { patients }\end{array}$ \\
\hline $\begin{array}{l}\text { Oct. 1, } \\
2005\end{array}$ & CCM & Ontario & $\begin{array}{l}\text { - FFS as usual } \\
\text { - Comprehensive-care capitation for } \\
\text { enrolled patients } \\
\text { - Incentives and bonuses } \\
\text { - After-hours premium }\end{array}$ & Solo & $\begin{array}{l}\text { - After-hours requirements } \\
\text { - Enrolment is optional, though } \\
\text { eligibility for many incentives } \\
\text { based on services to enrolled } \\
\text { patients }\end{array}$ \\
\hline $\begin{array}{l}\text { Nov. } 1 \\
2006\end{array}$ & $\begin{array}{l}\text { Family Health } \\
\text { Organization } \\
\text { (FHO) }\end{array}$ & Ontario & - See FHNs above & $\begin{array}{l}\text { Groups of three or } \\
\text { more physicians }\end{array}$ & - See FHNs above \\
\hline
\end{tabular}

83 Established in 2001 as Ontario Family Health Networks (OFHNs).

${ }^{84}$ In 2002, when the model was introduced, the group requirement was five or more physicians; however, when from 2003 onwards, many FHGs converting to FHNs were having trouble finding a fourth and fifth physician to join the group, the ministry lowered the minimum FHN group requirement to three. 


\section{APPENDIX 2: PAYMENT ELEMENTS FOR FFS, FHO AND FHG}

\section{Traditional FFS}

Number of Practitioners: 5,109 in 2005/06; 3,603 in 2009/10, approximately 3,500 in 2013.

Minimum Number of Physicians per Group: Not a group.

Co-operation Between Physicians: None required.

Enrolment: None.

After-hours Care Obligations: None.

Payment Streams: Standard rates in Schedule of Benefits plus the incentives below.

\section{Payment Elements that Apply to All Physicians (Including FFS):}

- Complex/geriatric-care Premium: 15 per cent premium for eight (comprehensive) billing codes for patients over 65 years of age; the codes are: A003, A007, A903, C003, C903, W102, W109 and W903 (accompanying code is E070/1). ${ }^{85}$

- Diabetes-management Incentive: \$75 yearly per patient for co-ordinating care of patient diagnosed with diabetes ${ }^{86}$ (accompanying code Q040).

- Add-on Initial Smoking Cessation Fee: $\$ 15.40$ for dialogue about smoking cessation with a patient who smokes (code E079).

- Smoking Cessation Counselling Premium of $\$ 7.50$ for up to two visits after smoking cessation (accompanying billing code Q042).

- Colorectal-cancer Screening Incentives:

- FOBT DISTRIBUtION AND COUNSEluING FEE: $\$ 7$ incentive payment to provide FOBT kits once per patient every two years, for all patients at risk of colorectal cancer (accompanying fee code Q150).

- FOBT COMPLEtION FEE: $\$ 5$ incentive payment when the patient's FOBT results have been reviewed by the physician and communicated to the patient. May be billed once every two years per patient. Can only be claimed if minimum roster sizes have not been met (accompanying fee code Q152).

- Out-of-Office Bonuses: Up to $\$ 11,000^{87}$ for:

- HOME VISITS: $\$ 1,000$ for a minimum of three patients and 12 visits or $\$ 2,000$ for a minimum of six patients and 24 visits.

- LONG-TERM CARE: $\$ 2,000$ for 12 or more patients.

- LABOUR AND DELIVERY: $\$ 5,000$ for five or more patients.

- Palliative care: $\$ 2,000$ for four or more patients.

85 Please note that in this section we do not list the suffix for any fee code as it intended to always be "A" which indicates the attending physician. For example, by "A003" we mean "A003A."

86 This was originally $\$ 60$ and increased to $\$ 75$ on April 1, 2009.

87 Physicians in FHGs and FHOs and other harmonized models are also eligible for higher levels of payments; see FHGs below for more details. 


\section{Family Health Groups (FHGs)}

Number of Practitioners: 3,412 in 2005/06, 4,322 in 2006/07, 3,941 in 2009/10. As of Nov. 1, 2013: 233 groups, 2,752 physicians and 3,362,774 enrolled patients.

Minimum Number of Physicians per group: Minimum three. Although there must be geographic proximity, the physicians do not need to be located in the same physical office space.

Co-operation Between Physicians: Must share medical records amongst all physicians in the group.

Enrolment: Not required but encouraged as most premiums are only paid for enrolled patients.

After-hours Care Obligations: Physicians must agree to provide after-hours care (Monday to Thursday evenings with a start time between 5 and 7 p.m. or on weekends) for a minimum of three hour-blocks per physician in the group to a maximum of 25 blocks for groups with 200 or more physicians. This time may be divided between the physicians according to their preferences. Since 2007, this obligation may be waived if more than 50 per cent of the FHG's practitioners work in hospital ERs, provide public-hospital anesthesia services, or provide regular after-hours obstetrical services.

Payment Streams: Standard rates in Schedule of Benefits, but physicians in these models also receive premiums and bonuses for providing rostered/enrolled patients with after-hours care and "comprehensive care," and meeting pay-for-performance targets. See above (payment for all physicians) and below for more details on individual payment elements.

Comprehensive-care incentives for creating, managing and maintaining appropriate medical records. The physician must provide or co-ordinate chronic-disease management.

- comprehensive-care management fee (also referred to as Comprehensive Care Capitation Fee): Physicians providing after-hours block coverage initially are eligible for an age- and sex-adjusted yearly capitation payment of $\$ 20$ on average per enrolled patient. This payment moves to about $\$ 26$ annually 12 months after signing the CCM Agreement. If a physician's roster exceeds 2,400 formally enrolled patients, the fees are reduced by half.

- COMPRehensive-CARE PREmium: 10 per cent premium for $33^{88}$ codes provided to enrolled patients; services include, for example, supportive care, HIV care, diabetes management, palliative care, immunizations, mini-assessment, and home visits.

- COMPLEX/GERIATRIC-CARE PREMIUM on comprehensive-care capitation payments of 15 per cent for patients aged 65 or older.

${ }^{88}$ Fee codes included in this premium were initially 13; i.e.: A003, A888, A901, E075, G365, G538, G590, G591, K005, K013, K017, A001 and A007. The following nine codes were added as of April 1, 2006: C010, K022, K030, K023, C882, G539, A008, A901 and A902. As of Sept. 1, 2011, nine new immunization codes became eligible for the premium: G840 to G848. As of Jan. 1, 2013, three new codes replaced A003: K130, K131 and K132 (periodic health visits for adolescents, adults, and seniors, respectively). 


\section{Patient Registration Incentives:}

- Per-Patient Enrolment Fee: \$5 per patient for the first year only following initial signing of contract (accompanying code Q200).

- Unattached Patient Fee of $\$ 150$ for acute-care patients discharged from hospital and without an existing primary care physician; no patient maximum (code Q023).

- New Graduate-New Patient Incentives: New graduates are allowed to bill a new patient declaration fee of $\$ 100, \$ 120$ for patients aged 65 to 74 and $\$ 180$ for patients aged 75 or over. This per-patient fee is available for rostering up to 300 (was 150 in the 2004-08 PSA) new patients (accompanying shadow billing code Q033).

- New Patient Premium: $\$ 100$ each for "formally enrolled new patients, without a physician" per year; $\$ 120$ for new patients aged 65-74; and \$180 for patients aged 75 and over for up to 60 new patients (accompanying shadow-billing code Q013). Increased fees of, respectively, $\$ 150, \$ 170$ and $\$ 230$ for enrolling a new patient with a positive FOBT result (code Q043).

- \$350 one-time payment of for Complex/Vulnerable New Patient Fee (effective April 2009), for attaching patients registered in the Health Care Connect program (code Q053), no patient maximum, plus 150 per cent of FFS for services provided to this patient during the first year.

- Unattached Mother and Newborn(s) (effective April 2009): \$350 for attaching mother and newborn (code Q054) to the practice within two weeks of birth and rostering them within three months; in case of multiple births, an additional $\$ 150$ is paid per additional infant (Q055).

\section{Premiums and Bonuses}

- Cumulative Preventive-Care Management Bonuses: Up to $\$ 12,800$ in total for:

- FLU SHOTS TO SENIORS: \$220, \$440, \$770, \$1,100 and \$2,200 for immunizing, respectively, $60,65,70,75$ or 80 per cent of eligible patients (codes Q100 to Q104).

- PAP SMEARS: $\$ 220, \$ 440, \$ 660, \$ 1,320$ and $\$ 2,200$ for screening, respectively, $60,65,70$, 75 or 80 per cent of eligible patients (codes Q105 to Q109).

- MAMmograms: $\$ 220, \$ 440, \$ 770, \$ 1,320$ and $\$ 2,200$ for screening, respectively, 55, 60 , 65, 70 and 75 per cent of eligible patients (codes Q110 to Q114).

- CHILDHOOd IMmUNIZATIONS: \$440, \$1,100 and \$2,200 for immunizing, respectively, 85, 90 and 95 per cent of eligible toddlers (codes Q115 to Q117).

- COLORECTAL-CANCER SCREENING (FOBT): $\$ 220, \$ 440, \$ 1,100, \$ 2,200, \$ 3,300$ and $\$ 4,000$ for screening, respectively, 15, 20, 40, 50,60 or 70 per cent of eligible patients (codes Q118 to Q123). 
- Out-of-Office Bonuses: Up to $\$ 23,000$ for:

- HOME VISITS: $\$ 1,000$ for a minimum of three patients and 12 visits; or $\$ 2,000$ for a minimum of six patients and 24 visits; $\$ 5,000$ for minimum of 17 patients and 68 visits.

- LONG-TERM CARE: $\$ 2,000$ for 12 or more patients; $\$ 5,000$ for 36 or more patients.

- LABOUR AND DeLIVERY: $\$ 5,000$ for five or more patients; $\$ 8,000$ for 23 or more patients.

- PallaAtive care: $\$ 2,000$ for four or more patients; $\$ 5,000$ for 10 or more patients.

- Special Payment:

- PRIMARY health CARE OF PATIENTS WITH SERIOUS MENTAL ILLNESS: $\$ 1,000$ annually for five to nine registered patients and $\$ 2,000$ for 10 or more patients (code Q020).

- After-hours Care: 30 per cent ${ }^{89}$ FFS supplement for after hours to ministry-rostered (virtually rostered) and formally enrolled patients for 14 office visit codes ${ }^{90}$ (accompanying fee code Q012).

- Congestive-Heart-Failure Management Incentive: \$125 per enrolled patient annually.

\section{Other Payments}

- On-call monthly payment of $\$ 1,000$ for groups of fewer than 10 physicians and $\$ 2,000$ to groups with more than 10 .

- Rurality gradient: Annual payment of $\$ 5,000$ per physician with a Rurality Index of Ontario (RIO) score between 40 and $49,{ }^{91}$ increasing by $\$ 1,000$ for each further score of five on the rurality index. The RIO is based on census sub-division and ranges from one to 100 . The vast majority of the province's population has a score less than five.

\section{Family Health Organizations (FHOs)}

Established in November 2006. All existing Health Service Organizations (HSOs) and Primary Care Networks (PCNs) were converted in FHOs and new FHOs were created.

Number of Practitioners: 315 physicians in November 2003 (HSOs and PCNs), 331 in January 2007, 3,264 in September 2010. Number of patients enrolled: 530,604 in November 2003 (HSOs and PCNs), 558,544 in January 2007 and 4,818,383 in September 2010. As of Nov. 1, 2013: 420 groups, 4,451 physicians and 5,918,831 patients rostered.

89 Originally, the premium was 10 per cent; it increased to 15 per cent (April 2005), then to 20 per cent (April 2006) and, as of Sept. 12011 increased again to 30 per cent (MOHLTC Bulletin 11020).

90 Originally the codes were six: A001, A003, A004, A007, A008 and A888. Three codes were added April 1, 2005: K005, K013 and K017. Codes K030 (diabetes management) and Q050 (management of heart failure) were added on April 2009. We are unsure of the date on which K033 became eligible for this premium (MOHLTC Bulletin 11020). On Jan. 1, 2013, three additional codes were added and replaced A003 with K130, K131 and K132.

91 Prior to April 2009, the minimum RIO score for this premium was 45. 
Minimum Number of Physicians per Group: Same as FHGs (above).

Co-operation Between Physicians: Same as FHGs.

Enrolment: Requirement of 2,400, 3,200 or 4,000 patients for groups of three, four or five physicians, respectively.

After-hours Care Obligations: Same as FHGs.

\section{Payment streams:}

- Capitation for core services to enrolled patients: Age- and sex-adjusted average set at $\$ 132.25$ for 125 codes. The base rate is reduced by 50 per cent for patients beyond an average of 2,400 patients per physician. Higher rates and not age- and sex-adjusted, for patients in a long-term care facility.

- Shadow-billing premium of 15 per cent for the above services.

- An access bonus of 18.59 per cent of the total capitation payments is paid semi-annually, 20.65 per cent access bonus for capitation payment for patients residing in a long-term care facility.

- FFS payments for core services provided to non-enrolled patients capped at $\$ 52,883$.

\section{All other payment streams are the same as FHGs except for the following:}

- No comprehensive-care premium for FHOs

- Complex/Vulnerable patient: The 150 per cent of FFS paid to FHGs is replaced with a $\$ 500$ payment added to the yearly capitation rate for patients rostered through this initiative.

- Additional Special Payments: Up to $\$ 11,500$ for:

- HOSPITAL SERVICES: $\$ 5,000$ or $\$ 7,500$ if in a rural area with RIO higher than 40 for providing $\$ 2,000$ in hospital services.

- PREnatal CARE: $\$ 2,000$ for providing care to five or more enrolled patients.

- OFFICE PROCEDURES: $\$ 2,000$ for providing at least $\$ 1,200$ in office procedures.

- Newborn-care Episodic Fee: Bonus of $\$ 13.99$ for each of up to eight baby-care visits for babies less than one year old (code Q015).

- Continuing Medical Education for conferences and seminars, 24 hours maximum per year, $\$ 100$ per hour (code Q555).

- Income stabilization during the first year as a newly transitioned FHO physician: Guaranteed minimum FFS income.

- Group Management and Leadership Payment: \$1 per patient per year to a $\$ 25,000$ maximum.

- Office Practice Administration Grant: One-time grant between $\$ 12,500$ and $\$ 25,000$ paid to the group and depending on size of the group. 



\title{
ABOUT THE SCHOOL OF PUBLIC POLICY
}

The School of Public Policy will become the flagship school of its kind in Canada by providing a practical, global and focused perspective on public policy analysis and practice in areas of energy and environmental policy, international policy and economic and social policy that is unique in Canada.

The mission of The School of Public Policy is to strengthen Canada's public service, institutions and economic performance for the betterment of our families, communities and country. We do this by:

- Building capacity in Government through the formal training of public servants in degree and non-degree programs, giving the people charged with making public policy work for Canada the hands-on expertise to represent our vital interests both here and abroad;

- Improving Public Policy Discourse outside Government through executive and strategic assessment programs, building a stronger understanding of what makes public policy work for those outside of the public sector and helps everyday Canadians make informed decisions on the politics that will shape their futures;

- Providing a Global Perspective on Public Policy Research through international collaborations, education, and community outreach programs, bringing global best practices to bear on Canadian public policy, resulting in decisions that benefit all people for the long term, not a few people for the short term.

\author{
The School of Public Policy \\ University of Calgary, Downtown Campus \\ 906 8th Avenue S.W., 5th Floor \\ Calgary, Alberta T2P $1 \mathrm{H} 9$ \\ Phone: 4032107100
}

\section{DISTRIBUTION}

Our publications are available online at www.policyschool.ca.

\section{DISCLAIMER}

The opinions expressed in these publications are the authors' alone and therefore do not necessarily reflect the opinions of the supporters, staff, or boards of The School of Public Policy.

\section{COPYRIGHT}

Copyright (C) 2014 by The School of Public Policy.

All rights reserved. No part of this publication may be reproduced in any manner whatsoever without written permission except in the case of brief passages quoted in critical articles and reviews.

\section{ISSN}

1919-112x SPP Research Papers (Print)

1919-1138 SPP Research Papers (Online)

\section{DATE OF ISSUE}

April 2014

\section{MEDIA INQUIRIES AND INFORMATION}

For media inquiries, please contact Morten Paulsen at 403-453-0062. Our web site, www.policyschool.ca, contains more information about The School's events, publications, and staff.

\section{DEVELOPMENT}

For information about contributing to The School of Public Policy, please contact Courtney Murphy by telephone at $403-210-7201$ or by e-mail at cdmurphy@ucalgary.ca. 


\section{RECENT PUBLICATIONS BY THE SCHOOL OF PUBLIC POLICY}

THE MIDDLE POWER AND THE MIDDLE KINGDOM: SECURING CANADA'S PLACE IN THE NEW CHINA-U.S. ECONOMIC AND STRATEGIC WORLD ORDER $\mathrm{http}: / /$ policyschool.ucalgary.ca/?q=content/middle-power-and-middle-kingdom-securing-canadas-place-new-china-us-economic-and-strategic-w Wendy Dobson | April 2014

SAFETY IN NUMBERS: EVALUATING CANADIAN RAIL SAFETY DATA

http://policyschool.ucalgary.ca/?q=content/safety-numbers-evaluating-canadian-rail-safety-data

Jennifer Winter | April 2014

CHINA'S STATE-OWNED ENTERPRISES AND CANADA'S FDI POLICY

http://policyschool.ucalgary.ca/?q=content/chinas-state-owned-enterprises-and-canadas-fdi-policy

Wendy Dobson | March 2014

THE TAMING OF THE SKEW: FACTS ON CANADA'S ENERGY TRADE

http://policyschool.ucalgary.ca/?q=content/taming-skew-facts-canadas-energy-trade

Trevor Tombe | March 2014

CANADA-KOREA FREE TRADE: A WATERSHED IN ECONOMIC INTEGRATION WITH ASIA

http://policyschool.ucalgary.ca/?q=content/canada-korea-free-trade-watershed-economic-integration-asia

Eugene Beaulieu | March 2014

KEEPING THE GENIE IN THE BOTILE: GRADING THE REGULATION OF CANADIAN FINANCIAL INSTITUTIONS

http://policyschool.ucalgary.ca/?q=content/keeping-genie-bottle-grading-regulation-canadian-financial-institutions

John Chant | March 2014

SIMULATED REPLACEMENT RATES FOR CPP REFORM OPTIONS

http://policyschool.ucalgary.ca/?q=content/simulated-replacement-rates-cpp-reform-options

Kevin Milligan and Tammy Schirle | March 2014

ABORIGINAL-CANADIANS AND ENERGY LITERACY: A SURVEY OF OPINIONS AND THOUGHTS ON ENERGY

http://policyschool.ucalgary.ca/?q=content/aboriginal-canadians-and-energy-literacy-survey-opinions-and-thoughts-energy

Michal C. Moore, André Turcotte and Jennifer Winter | February 2014

THE RISE AND FALL OF SOCIAL ASSISTANCE USE IN CANADA, 1969-2012

http://policyschool.ucalgary.ca/?q=content/rise-and-fall-social-assistance-use-canada-1969-2012

Ron Kneebone and Katherine White | February 2014

INCOME ADEQUACY AMONG CANADIAN SENIORS: HELPING SINGLES MOST

http://policyschool.ucalgary.ca/?q=content/income-adequacy-among-canadian-seniors-helping-singles-most

Philip Bazel and Jack Mintz | February 2014

ENERGY EFFICIENCY: FINDING LEADERSHIP OPPORTUNITIES

http://policyschool.ucalgary.ca/?q=content/energy-efficiency-finding-leadership-opportunities

William D. Rosehart and Hamidreza Zareipour | February 2014

SHOULD CANADA WORRY ABOUT A RESOURCE CURSE?

http://policyschool.ucalgary.ca/?q=content/should-canada-worry-about-resource-curse

Alan Gelb | January 2014

PRIORITIZING DEFENCE INDUSTRY CAPABILITIES: LESSONS FOR CANADA FROM AUSTRALIA

$\mathrm{http}: / /$ policyschool.ucalgary.ca/?q=content/prioritizing-defence-industry-capabilities-lessons-canada-australia

Craig Stone | January 2014 